\title{
Systematic and Phylogenetic Analysis of the Ole e 1 Pollen Protein Family Members in Plants
}

\author{
José Carlos Jiménez-López, \\ María Isabel Rodríguez-García and Juan de Dios Alché \\ Department of Biochemistry, Cell and Molecular Biology of Plants \\ Estación Experimental del Zaidin, CSIC, Granada,
}

Spain

\section{Introduction}

Pollen allergens are specific substances able to cause IgE-mediated hypersensitivity (allergy) after contact with the immune system [D'Amato et al. 1998]. To date, about 50 plant species have been registered in the official allergen list of the International Union of Immunological Societies (IUIS) Allergen Nomenclature Subcommittee http://www.allergen.org as capable of inducing pollen allergy in atopic individuals [Mothes et al. 2004]. These plants are usually grouped as (1) trees (members of the orders: Fagales, Pinales, Rosales, Arecales, Scrophulariales, Junglandales, Salicales, and Myrtales), (2) grasses (members of the families: Bambusioideae, Arundinoideae, Chloridoideae, Panicoideae, and Poideae), and (3) weeds (components of families Asteraceae, Chenopodiaceae and Urticaceae) [Hauser et al. 2010].

Allergens are proteins with a broad range of molecular weights ( $\sim 5$ to $50 \mathrm{kDa})$, which exhibit different features of solubility and stability. More than 10 groups of pollen allergens have been reported. Among all groups of pollen allergens, Pollen Ole e I (Ole) domaincontaining proteins are the major allergens, included like-members of the "pollen proteins of the Ole e 1 family" (Accession number: PF01190) within the Pfam protein families database [Finn et al. 2010].

Ole e 1 was the first allergen purified from Olea europaea L. [Lauzurica et al. 1998] and named as such according to the IUIS nomenclature [King et al. 1994]. This protein is considered the major olive pollen allergen on the basis of its high prevalence among atopic patients and the high proportion it represents within the total pollen protein content, in comparison with other olive pollen allergens. These include at present another 10 allergens already identified and classified like Ole e 2 to Ole e 11 [Rodríguez et al. 2002, Barral et al. 2004, Salamanca et al. 2010]. Ole e 1 consists of a single polypeptide chain of 145 amino acid residues with a MW of $18-22 \mathrm{kDa}$, displaying acidic $\mathrm{pI}$ and different forms of $\mathrm{N}$ glycosylation [Villalba et al. 1990, Batanero et al. 1994]. Heterologous proteins with a relevant homology have been described in other members of the Oleaceae family, such a fraxinus, lilac, jasmine and privet. The polypeptides encoded by the LAT52 gene from tomato and the Zmc13 gene from maize pollens also exhibit a high similarity to Ole e 1 [Twell et al. 1989, Hanson et al. 1989]. These plant pollen proteins are structurally related but their biological function is not yet known; though they have been suggested to be 
involved in important events of pollen physiology, such as hydration, germination and/or pollen tube growth, and other reproductive functions [Alché et al. 1999, 2004, Tang et al. 2000, Stratford et al. 2001].

Structurally, the Ole domain contains six conserved cysteines which may be involved in disulfide bonds, since no free sulfhydryl groups have been detected in the native protein [Villalba et al. 1993]. Olive Ole e 1 exhibits a high degree of microheterogeneity, mainly concentrated in the third of the molecule closer to the N-terminus. The Ole e I (Ole) domain defining the pollen proteins Ole e I family signature or consensus pattern sequences PS00925 [Sigrist et al. 2010], is characterized by the amino acid sequence [EQT]-G-x-V-Y-C-D-[TNP]C-R, where " $x$ " could be any residue.

There is a high diversity of proteins sharing the Ole domain among plant species. To date, eleven Ole domain-containing genes have been isolated and characterized from olive pollens [Rodríguez et al. 2002]. Ole-containing proteins include proline-rich proteins, proteins encoding extensin-like domains, phosphoglycerate mutase, tyrosine-rich hydroxyproline-rich glycoprotein, and hydroxyproline-rich glycoprotein. These Olecontaining proteins can exhibit: (1) the pollen Ole signature exclusively, e.g. the ALL1_OLEEU P19963 protein from Olea europaea L., (2) both the pollen Ole signature and the replication factor A protein 3 motive pattern (PF08661), e.g. the O49527 pollen-specific protein-like from Arabidopsis thaliana (842 residues), (3) both the pollen Ole domain and the phosphoglycerate mutase (PGAM) motif, e.g. the Q9SGZ6 protein from Arabidopsis thaliana., and finally (4) both the pollen Ole signature and the reverse transcriptase 2 (RVT2) motif, e.g. the A5AJL0 protein from Vitis vinifera.

Several efforts have been made to develop an understandable and reliable systematic classification of the diverse and increasing number of different allergen protein structures. As mentioned above, the classification system widely established for proteins that cause IgE-mediated atopic allergies in humans (allergens) was defined by Chapman et al. (2007). This system uses the first three letters of the genus; a space; the first letter of the species name; a space and an Arabic number. Despite this classification system, protein databases are full of allergen proteins lacking this systematic and comprehensive nomenclature. In other cases, many of the proteins described here have not been described as allergens, or their naming makes no reference to the Ole e 1 family that facilitates their identification. Otherwise, naming in databases is frequently given randomly, on the basis of chromosome location, addressing structural features and functional characterizations or simply using the name of the entire family. In this study, we used a combination of functional genomics and computational biology to name and classify the entire Ole e 1 family, as well as to characterize structurally and functionally the proteins of this superfamily. Our data indicate that the Ole e 1 protein family consists of at least 109 divergent families, which will likely expand as more genomic studies are undertaken, and fully sequenced plant genomes become available.

\section{Material and methods}

\subsection{Database search for Ole e 1 family genes}

Sequences of Ole e 1 and Ole e 1-like genes were retrieved from the US National Center for Biotechnology Information (NCBI, http://www.ncbi.nlm.nih.gov/ ), the Uniprot database (http://www.uniprot.org/), and the non-redundant expressed sequence tag (EST) 
databases using BLASTX, BLASTN and BLAST (low complexity filter, Blosum62 substitution matrix) [Altschul et al. 1997]. Searches were conducted using previously characterized Olea europaea L. Ole e 1 (GenBank Accession number P19963), Solanum lycopersicum LAT52 (GenBank Accession number P13447), Zea mays Zmc13 (GenBank Accession number B6T1A9), Arabidopsis thaliana pollen-specific protein-like (GenBank Accession number O49527), Arabidopsis thaliana PGAM containing domain protein (GenBank Accession number Q9SGZ6), and Vitis vinifera RVT2 containing domain protein (GenBank Accession number A5AJL0). Full-length amino acid sequences for Ole e 1 proteins were compiled and aligned using ClustalW [Thompson et al. 1994]. Genetic distances between pairs of amino acid sequences were calculated with Bioedit V7.0.5.3 [Hall 1999]. Consensus protein sequences were derived from these original alignment, and further analyzed for the presence of putative functional motifs using the PROSITE database [Sigrist et al. 2010], of biologically meaningful motif descriptors derived from multiple alignments and the ScanProsite program [de Castro et al. 2006], from the Expert Protein Analysis System (ExPASy) proteomics server of the Swiss Institute of Bioinformatics [Gasteiger et al. 2003]. Finally, the consensus protein sequences were submitted to BLASTP analysis to identify homologous proteins from other plant species.

\subsection{Revised/unified nomenclature}

In order to provide a revised and unified nomenclature for Ole e 1-like gene superfamily, we developed a sequence-based similarity approach to classify all the retrieved sequences using a previously developed gene nomenclature model [Kotchoni et al. 2010]. For this new nomenclature, Ole e 1 protein sequences that are more than $40 \%$ identical to previously identified Ole e 1 sequences compose a family, and sequences more than $60 \%$ identical within a family, compose a gene subfamily. Protein sequences that are less than $40 \%$ identical would describe a new Ole e 1 gene family. Taking olive protein Ole e 1_57A9 (previous name Ole e 1, major olive pollen allergen) as an example for the revised nomenclature (Table 1), Ole e 1 indicates the root; the digits (57) indicates a family and the first letter (A) a subfamily, while the final number (9) identifies an individual gene within a subfamily. The revised nomenclature is therefore composed of an assigned gene symbol (Ole e 1) (abbreviated gene name) for the whole gene superfamily. The gene symbol must be (i) unique and representative of the gene superfamily; (ii) contain only Latin letters and/or Arabic numerals, (iii) not contain punctuation, and (iv) without any reference to species. These newly developed criteria have been applied to database curators to generate the unified Ole e 1 gene families/classes regardless of the source of the cloned gene(s).

\subsection{Sequence alignments and phylogenetic analyses}

The retrieved Ole e 1 protein families were used to generate a phylogenetic tree using ClustalW [Thompson et al. 1994]. The alignment was created using the Gonnet protein weight matrix, multiple alignment gap opening/extension penalties of $10 / 0.5$ and pairwise gap opening/extension penalties of 10/0.1. These alignments were adjusted using Bioedit V7.0.5.3 [Hall 1999]. Portions of sequences that could not be reliably aligned were eliminated. Phylogenetic tree was generated by the neighbourjoining method (NJ), and the branches were tested with 1,000 bootstrap replicates. The three was visualized using Treedyn program [Chevenet et al. 2006]. 


\subsection{Ole e 1 superfamily: Protein modeling and structural characterization}

In order to study the structural and conformational variability between the Ole e 1 protein families, selected members of the Ole e 1 superfamily were modelled using SWISS-MODEL server, via the ExPASy web server [Gasteiger et al. 2003]. The initial modelled Ole e 1 structures were subjected to energy minimization with GROMOS96 force field energy [van Gunsteren et al. 1996] implemented in DeepView/Swiss-PDBViewer v3.7 [Guex and Peitsch 1997] to improve the van der Waals contacts and to correct the stereochemistry of the improved models. The quality of the models was assessed by checking the protein stereology with PROCHECK [Laskowski et al. 1993] and the protein energy with ANOLEA [Melo et al. 1997, 1998]. Ramachandran plot statistics for the models were calculated to show the number of protein residues in the favoured regions.

\section{Results}

\subsection{The Ole e 1 protein families: Revised and unified nomenclature}

In order to provide a revised/international consensus and unified nomenclature for the Ole e 1 gene superfamily, we first retrieved all the Ole e 1 and Ole e 1-like gene sequences using PS00925 as the major molecular consensus defining the entire superfamily of Ole e 1 proteins. We next verified all annotated plant Ole e 1 open reading frames (ORFs) using Ole e 1 sequence domains. A complementary and comparative study was developed by using Uniprot database to validate the molecular function and previous denomination of each Ole e 1 protein. Our searches resulted in the identification of 571 sequences encoding Ole e 1 and Ole e 1 like proteins from a wide variety of plant species, with the diagnostic motif PS00925 (Table 1). According to the established criteria (see Material and Methods), these sequences integrated 109 Ole e 1 gene families which have been attributed to different functional categories including extensins and extensin-like proteins, proline-rich proteins, hydroxyproline-rich glycoproteins, tyrosine-rich/hydroxyproline-rich glycoproteins, hydrolases, phosphoglycerate mutases, arabinogalactan proteins, etc. (Table 1).

Among the sequences retrieved, Ole e 1_48 is the most extensive family with 63 gene members encoding for different pollen-specific protein $\mathrm{C} 13$ homologues, followed by Ole e 1_57 family with 42 gene homologues encoding Ole e 1 (the olive major pollen allergen), Ole e 1_16 with 26 gene members encoding proline-rich proteins, and Ole e 1_52 with 22 members encoding LAT52 homologues (Table 1). The number of Ole e 1 genes greatly varied from one plant species to another. The genus Oryza included the highest number of Ole e 1 genes (143), followed by Arabidopsis with 95 genes (Table 1). At present, more than half of the catalogued Ole e 1 families encoded a single Ole e 1/Ole e 1-like gene, which was in most cases "uncharacterized" (Table 1).

The total number of genes in the Ole e 1 superfamily is expected to increase steadily with time, mainly due to the genomic sequencing of additional species like Olea europaea L. (http://www.gen-es.org/11_proyectos/PROYECTOS.CFM?pg=0106\&n=1 ). Regardless of the plethora of Ole e 1 genes yet to be identified/characterized, their classification and relationship to the entire extended Ole e 1 gene superfamily will be easy owing to this nomenclature building block that catalogues newly identified/characterized Ole e 1 gene products only on the basis of sequence similarity to previously characterized Ole e 1 gene products. 


\begin{tabular}{|c|c|c|c|c|}
\hline $\begin{array}{l}\text { The } \\
1 \\
1 \\
\text { ranily }\end{array}$ & $\begin{array}{l}\text { Resueas } \\
\text { armofayor }\end{array}$ & Pressous ennotailed & 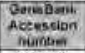 & Smarts \\
\hline 1 & Oinetsat & AdqgणZZ15 & QERXZZ & ARATH \\
\hline 1 & Ole $11.1 A_{2}$ & + & O8LRV & ARATH \\
\hline 9 & Gle $01,1 \mathrm{AJ}$ & ARAL YDRAPT 493155 & DTMC15 & ARALY \\
\hline 1 & Oles $1,1 / 4$ & 40,00006 & GzAgES & BRAOL \\
\hline 1 & D/A.1_IAS & 31,00000 & OZA2F5 & BRAOt \\
\hline 1 & Ofe 01 184 & ARALYOFAAFT_ATS053 & DTLEF & ARALY \\
\hline 1 & $0 \ln =1.182$ & Arzogat13 & QS\%FY & ARATH \\
\hline 1 & Cleet_tis & 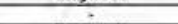 & OWLEG & ARATH \\
\hline 1 & Ote $=1.184$ & A15047635 & O29Pग & ARATH \\
\hline$T$ & OfeectiBs & ARALYDRAFT 330672 & DIRPZG & ARALY \\
\hline 2 & OHESt Z2A] & POPTRDRAFT BIE026 & BOHCDO & POPTK \\
\hline 2 & Oin o1 2A2 & POPTRDEATT TIGIII & BOIHTE & POPTR \\
\hline$z$ & Ole 01781 & 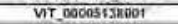 & $0755 k 5$ & VITV \\
\hline 2 & OientzCt & - & Cetses & Sorta \\
\hline 2 & Ole 61201 & 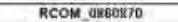 & BSSAEB & FacCO \\
\hline 3 & Ole 11341 & 0 si_ 33016 & 898644 & ORYS: \\
\hline 3 & ORA $=1,3 A 2$ & 051000206500 & $2109 \times 3$ & OAYS \\
\hline$\frac{5}{3}$ & $0 \ln =1 \mathrm{~s} 81$ & 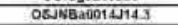 & DTGTEI & ONVS \\
\hline 3 & C4e of 382 & Ojroal F02. & gakv11 & ORYSI \\
\hline 3 & Oite $13 C$ I & OSJNBaOPALJ14.20 & OMsaun & ORYSI \\
\hline$\frac{3}{3}$ & 01601 301 & $0 s+090200600$ & स०खरा & ORYSU \\
\hline$\frac{7}{3}$ & OA6 of 302 & Ost 13026 & Bge053 & ORYSI \\
\hline$\frac{5}{3}$ & 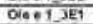 & 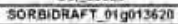 & CSWA75 & उOAब \\
\hline 3 & Ole 1351 & 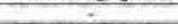 & SAFESG & MALZE \\
\hline$\frac{7}{4}$ & Oie E I SA1 & SELMODRAFT 444621 & Dasaks & SELML \\
\hline 4 & Ole ot 142 & SELLODKAFT 443115 & Oesoxy & SELML \\
\hline 5 & Ole 1 1 SA1 & ARAL YORAFT $411163 Y$ & DTLOXI & ARALY \\
\hline 5 & $060,15 \mathrm{SA2}$ & A17027385 & DEMLE & ARATH \\
\hline 5 & Ole o1 SB1 & 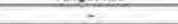 & C65vü & SOYEN \\
\hline 5 & Oin 51 682 & $=$ & CGITFA & SOYẼ \\
\hline$\frac{5}{5}$ & Oie 51 BCA & $=$ & C65201 & SOWBN \\
\hline 5 & Ode $=1$ SDI & POPTRDRAPT BZTSES & A9p15i & DOPTR \\
\hline 5 & 01001,502 & RCOIh $128+1170$ & Byscwa & RACCO \\
\hline 5 & O46e1_503 & VITSE_ IST1997 & ASBV12 & ทัज \\
\hline 5 & Oloot SE1 & A(3022430 & Q9FMal & ARATH \\
\hline 5 & 9001582 & $a$ & aILI/ & ARATH \\
\hline 5 & Oleet_SEX & ARALYDDAFT 151265 & Drmexs & ARALY \\
\hline E & Ole 11 BA1 & 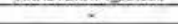 & B5r-91 & MAIZE \\
\hline 5 & OIBE1_6AR & $=$ & BAfOB & MAIZE \\
\hline
\end{tabular}

\begin{tabular}{|c|c|c|c|c|}
\hline 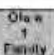 & $\begin{array}{l}\text { Rewsod } \\
\text { annotanon }\end{array}$ & Previpus anmaiatien & 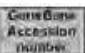 & Shercen \\
\hline 5 & Oin e1 661 & . & BетKH3 & MaIzE \\
\hline 5 & Ole 11 HiCA & 56049021840 & CSXTZI & 50\%स \\
\hline 5 & Dle 01 . 609 & (611200 0223 & QEEPWB & ORYSN \\
\hline 7 & Dle o1 7A1 & SELMOORAFT 405035 & DEAYSB & SELML \\
\hline$\frac{T}{7}$ & Dio01_tA? & SELMODRAFT_A4GA9 & DARTVS & SEIVL \\
\hline 8 & O6001 EA1 & SELMOORAFT_AA91Z9 & DSTAZI & SELML \\
\hline 8 & Oient 1 畹1 & SELMODRAFT $\triangle 0980$ S & DERCh & SELML \\
\hline$\pi$ & OWD o 1_BCT & SELMODRAFT_A191ZE & D\&Tazi & SELML \\
\hline 9 & Olive $1_{\text {_EA }}$ & A18gस140 & o9skp? & ARATH \\
\hline 9 & Ole 01.942 & Proine-iten protein 2 & Q9MाTण & ARATH \\
\hline 9 & Oia 01 1 ans & ARALYORAFT T0052J & DRLLO3 & ARALY \\
\hline 9 & Oine 1.981 & Extonsintien protein & Q9e16T6 & ARATH \\
\hline 9 & $\operatorname{Sin} \theta 1.962$ & Frilno-rieh pratein A & Oammata & AKATH \\
\hline i & Obe o 1 Jfas & ATAgBSTTOTEA14_BD & O9Tuis & ARATH \\
\hline y & Die 07 ges & ARAL YORAFT_A900A1 & D7MFN2 & ARALY \\
\hline (10) & Dle日, $10 A 1$ & Prolinerich protain & $0946 \pi$ & Nicol \\
\hline 10 & $00601.10 \mathrm{~B} 1$ & VIT 00024051004 & DTUSAO & VTV \\
\hline 10 & Olnat1.1082 & 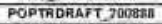 & BQHAAE & POPTR \\
\hline 10 & olen $1.10 \mathrm{CZ}$ & POPTRORAFT 195015 & Bent154 & POPTH \\
\hline 10 & Olo $=1,1002$ & RCOM ORिiC6 30 & BASTCS. & RACCO \\
\hline 11 & Oloei I11A1 & Proline-fich protein & 082060 & श्राप \\
\hline 12 & $06 \varepsilon 1,12 \mathrm{A1}$ & VITSV 029041 & ASADP2 & ทีบเ \\
\hline 13 & 01041,1341 & ทTा5V 1200438 & A5BOA & जाm \\
\hline 13 & Oin 01 ISA2 & vitov Brgary & A5BOPO & VTM \\
\hline 13 & Otw 11.1381 & VT 00624076001 & D7U5:47 & VTV \\
\hline 14 & Otoa1_14A1 & profline-rich prodein & Qस3WF & ORYEA \\
\hline 14 & ONe $=1.14 \mathrm{AZ}$ & 08600149900 & c7गा & ORYS \\
\hline 18 & $01061,10 \mathrm{A3}$ & meoline-tich protain & O93WL9 & ORYSA \\
\hline 14 & Oto.1.14Ai & Os 0000149600 & OTKGT3 & oAvs \\
\hline 14 & Oln E1.1SAS & prolinn-yich protein & Oeskis & ORYSA \\
\hline 14 & Dlo 1.14 .146 & Osiogo14970a & वाxaत & ORVSI \\
\hline 14 & Olo o1 14A7 & 0 os 30735 & $A^{2} \mathrm{CC2JB}$ & ORYSI \\
\hline 14 & Ole e $1,14 \mathrm{All}$ & OA1 12924 & A2XKEV & ORYSI \\
\hline 14 & $06061.14 \times 3$ & Osi_12923 & A2XKE) & ORYS: \\
\hline 14 & Gees 14A40 & os 12924 & BSAPZS & ORYS: \\
\hline 14 & des: 1,14A11 & OSJWBa0031A V7. & O24H17 & ORVSA \\
\hline 14 & DIQEI I 14A12 & $023 \quad 30737$ & $\mathrm{~A} 3 \mathrm{C} 2 \mathrm{Ka}$ & ORYSU \\
\hline 14 & 01001,14413 & Ostogl149400 & Q7XGTO & ORYSU \\
\hline 14 & ares.14614 & Osj 307734 & A.3C2K0 & ORYS \\
\hline
\end{tabular}

Table 1. The Ole e 1 protein superfamily: new and unified nomenclature. ARATH: Arabidopsis thaliana; ARALY: Arabidopsis lyrata; BETPN: Betula pendula; BRAOL: Brassica oleracea; BRARP: Brassica rapa; CAPAN: Capsicum annuum; CARAS: Cardaminopsis arenosa; CHE1: Chenopodium album; CROSA: Crocus sativus; DAUCA: Daucus carota; EUPPU: Euphorbia pulcherrima; FRAEX: Fraxinus excelsior; GOSBA: Gossypium barbadense; GOSHE: Gossypium herbaceum; GOSHI: Gossypium hirsutum; GOSKI: Gossypioides kirkii; HYAOR: Hyacinthus orientalis; LigVu: Ligustrum vulgare; LILLO: Lilium longiflorum; LOLPE : Lolium perenne; MAIZE: Zea mays; MEDTR: Medicago truncatula; NICAL: Nicotiana alata; NICGL: Nicotiana glauca; NicLa: Vitis pseudoreticulata; OleEu: Olea europaea; ORYSI: Oryza sativa; PETCR: Petroselinum crispum; PETHY: Petunia hybrida; PHAVU: Phaseolus vulgaris; PHEPR : Phleum pratense; PHYPA: Physcomitrella patens; PICSI: Picea sitchensis; PLALA: Platanus lanceolata; POPTR: Populus trichocarpa; RICCO: Ricinus communis; SALKA: Salsola kali; SAMNI: Sambucus nigra; SELML: Selaginella moellendorffii; SOLLI: Solanum lycopersicum; SOLTU: Solanum tuberosum; SORBI: Sorgum bicolor; SOYBN: Glycine max; TOBAC: Nicotiana tabacum; TRISU: Trifolium subterraneum; VITVI: Vitis vinifera; 9ROSI: Cleome spinosa; (-): uncharacterized. 


\begin{tabular}{|c|c|c|c|c|}
\hline 14 & O100 1 14A15 & OS.NBA,0031A07.9 & O94k14 & ORYSA \\
\hline 14 & OYe 1 1. 14A1E & QS1090149900 & QTKGS7 & ORYSI \\
\hline 14 & O4001_34A17 & $0 \times 32734$ & A2252I & CArs \\
\hline 14 & Ofoel.1401 & probinestich procesn & 994415 & OAYSA \\
\hline 14 & Ole of 14C & Os1000149600 & a7xos & OFVB. \\
\hline 14 & OCe of 1401 & Os 3079 & $\mathrm{ASCZKA}$ & OFVE \\
\hline$\pi$ & Oto. $114 \mathrm{EF}$ & 0 of 32753 & A22527 & ORYS \\
\hline 15 & $01001.15 \mathrm{~A} 1$ & $0 \times 230735$ & $\mathrm{~A}_{2 \mathrm{C} 2 \mathrm{KI}}$ & ORYSU \\
\hline 16 & Oie 01 16A1 & Dfolino-rich procein & Q94H12 & OAYSA \\
\hline 16 & Olo:1 SBA & probinesich profein & AKNAC? & OAYS: \\
\hline 16 & Ole 51 16A3 & Ostogonisod00 & OTXGS4 & OFYSA \\
\hline 16 & Ole o 1.16AA & Osi_32757 & A.22531 & OAYS: \\
\hline 16 & Ole of 16 . & aroline tich prokein & C94HUD & QRYSA \\
\hline 16 & Olee1, teAs & Os 1000150800 & ardas? & ORYSN \\
\hline 16 & $01901.16 \mathrm{~A} 7$ & opolinesich protein - & DaRWW6 & OAYsa \\
\hline $1 \mathrm{~B}$ & Ole 1 1 THAS & profilunesich prutein & Cos4to & ORVSA \\
\hline 16 & Ole:A1_TKAS & Ostegorisotor & a.xas3 & OFVE.I \\
\hline 16 & O900 1 16A10 & Oe 32759 & A.72533 & ORYS \\
\hline 16 & Ge01.16All & prodinefich prodein & AEABZOD & ORYS \\
\hline 16 & Ofoev ITAAR & Deolinortch protén & Q94साI & ORYSA \\
\hline 16 & 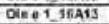 & 051009136600 & $0700 \times 1$ & Ders. \\
\hline 16 & DVEet IfFA14 & Prollus fich pusieln & A6N577 & OAYF \\
\hline It & Oteg 1 ISAES & Oed 32758 & A225132 & OAYS \\
\hline 16 & Gre 1.15A1E & Ost $327 \mathrm{E} 0$ & BMEFk7 & OHYS \\
\hline 16 & Ole e t iDA17 & LOC Osibgos990 & D33日1E & ORYSI \\
\hline 16 & olo o 1.1681 & Prolitios fich protein & O34+13 & ORYSA \\
\hline 16 & Q0001-16E? & Os1090150300 & a)xess & oars \\
\hline 16 & Ole of 16is3 & $0 \times 32756$ & A22530 & OAVs \\
\hline 16 & Oie ofikct & - & BESJAM & MAIZE \\
\hline 16 & Olo 1,1 IICL2 & 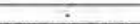 & BETBYS & MAIZE \\
\hline 16 & $01061,16 \mathrm{CJ}$ & Prolins tich oretein & B6TLL3 & MAIZE \\
\hline 16 & $01001,16 \mathrm{Cl}$ & 50069026190 & CSWP19 & SOREI \\
\hline 16 & $010=1.9001$ & . & GSUARS & MAIZE \\
\hline 1et & Ole * 1_16Ei & - & COPAEZ & MAIZE \\
\hline 11 & Olo of 17A4 & 5 boropas970 & CIWP1A & SOR日 \\
\hline 17 & $01001.17 \mathrm{Az}$ & Proline fich proteln & Oessaxa & MAIZE \\
\hline 18 & 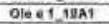 & 50019025770 & C5WP1E & SORE: \\
\hline 19 & Qloe1.13AT & Drofinofich procein & C94GB6 & ORYSA \\
\hline 18 & Ole o $1,19 A Z$ & Ostiogit4stion & Q7) $\times 078$ & ORVBI \\
\hline 10 & Ole of TIAA] & 0 - 1072 & Bag $/ d z$ & ORYE. \\
\hline 18 & Olest I I 15AA & $0 \mathrm{~d}, 224 \mathrm{3}$ & A.22324 & OKYA \\
\hline 19 & Oles1.1981 & & CAJABE & MAIZE \\
\hline
\end{tabular}

\begin{tabular}{|c|c|c|c|c|}
\hline 19 & Oto. 1 1582 & $=$ & BAFM91 & MAIZE \\
\hline 19 & Ole of 1989 & Proline-rich proldin & BपLसS & MAIZE \\
\hline 19 & 01001.4984 & Proling-ich prolein & C5WPZO & SOR日 \\
\hline 19 & Ole ot $19 \mathrm{Cl}$ & O4 10729 & A2XEH2 & OAYS \\
\hline 10 & Ola 01 1 & 050300245200 & GOPKS & OKVE⿱ \\
\hline 19 & OleOA 19EI & 50010041210 & Cswaz & SOREI \\
\hline 19 & Oleo1 19E2 & Proline flch prodain & E6TSEA & MAIZE \\
\hline 10 & OleO1_19E3 & Profinotich piovein & BAfOST6 & MAIZE \\
\hline 20 & Ole 612001 & Droinestich brokein & Q94Ges4 & OAYSA \\
\hline 70 & 010.01202 & Osingotatroo & $97 \times 6 \pi$ & akva. \\
\hline 20 & Ole ol 2003 & 02132750 & gasiski & ORYSI \\
\hline 21 & Ole $121 \mathrm{A1}$ & $0 \times 10730$ & A2XEH3 & ORYSI \\
\hline 21 & $010.1212^{2}$ & 0 S0200245300 & OTOPG4 & ORYS \\
\hline 21 & Ole of 2181 & 55019041220 & cswazi & SORB: \\
\hline 21 & 060122182 & Prolithorich proten & 86TJKI & GALE \\
\hline 22 & O1901,2ZAI & 0404502 & AZWXZK & OKYSI \\
\hline 22 & Ola $91,2 Z A Z$ & 080 r 09899700 & OSESVY & ORYSI \\
\hline 22 & $060122 \mathrm{AI}$ & $50030042 \pi 00$ & C5xFEA & इ0सष्ध \\
\hline 21 & Ole. 1234 & SELMOCRAFT $44 E K 7$ & Degtava & SELML \\
\hline 24 & Ole $01,24 \mathrm{A1}$ & SELMODRAFT_4A9ZO & DrTope & SELML \\
\hline 23 & Oloe1_25A & OH-proäna-fich givcopersein & Qweras & PHAVU \\
\hline 26 & Ole el aIA1 & TVr. OH-aroline dith glve optol. & 040793 & PETCE \\
\hline 27 & Oie $P 1,27 \mathrm{~A} 1$ & SELMOORAFT_A1099? & Dasast & SELML \\
\hline 27 & $0600127 A Z$ & SELMODFAFT $4271 Z 1$ & DasyKo & SELLML \\
\hline 28 & Ole 61 2BA1 & SELMODRAFT 441903 & DERMERO & SELML \\
\hline 78 & $01001,88 \mathrm{A2}$ & SELMOORAFT_ 40000 & D8T\$209 & SELML \\
\hline 28 & 010012081 & SELIMODRAFT_43ZI63 & O8R002 & SELIVL \\
\hline 28 & $\mathrm{Ota}=1,2 \mathrm{BB2}$ & BELMODKAFT 443338 & DETF 8 & SELWI \\
\hline 29 & Ola B 1 23A1 & SELMOORAFT_43BQDE & DAROOS & SELML \\
\hline 29 & $0100125 \mathrm{A2}$ & SELMOORAFT_439721 & OSRSC? & SELML \\
\hline 30 & OE $130 \mathrm{A1}$ & SELMOORAFT 44W(125 & D8T4022 & SELML \\
\hline ju & Ole e1,3tat & SELMODRAFT 413728 & D8RO13 & SELIML \\
\hline 31 & OiE e1 J1A2 & GELLODRRAFT_416536 & DERZL & BELML \\
\hline 32 & Ole of S2A1 & SEUMODRAFT_A1ES34 & DHRZL1 & SELML \\
\hline 32 & Ole =1 $122 A z$ & SELMODFAFT_ 413730 & DAFO1S & SELML \\
\hline 33 & O106133A1 & ARALVDRANT 48942 & DIMTO1 & ARALY \\
\hline 33 & Ole $6133 N_{2}$ & Aisy15190 & QBLFUR & ARATH \\
\hline 33 & Dige1 1381 & - & Q4KUY6 & 9ROS: \\
\hline 34 & OHAB $3 A A_{1}$ & 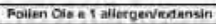 & Q2स8E9 & MEDTR \\
\hline 34 & Ola 11381 & 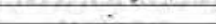 & Bifkis & MEDTR \\
\hline 24 & $000134 c 1$ & RCOM O/9050t & Bgav? & RाटC० \\
\hline 9 & 00.1 391 & VIT 00036543001 & D7RMMI & VMI \\
\hline
\end{tabular}

\begin{tabular}{|c|c|c|c|c|}
\hline j5 & Ole $=1$ 15A & MirDRACT ACI72742023Vi & A2057II & MEOT \\
\hline 36 & 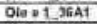 & POPTKDEAFT SEUEZI & BSN7MO & POPTK \\
\hline म1 & 0le of $37 \mathrm{Al}$ & Ox 35013 & A22353 & ORYSI \\
\hline 31 & 이 $01,37 \mathrm{AZ}$ & Ostog0205700 & AIVVOO & ORYSI \\
\hline 3T & O10. 1.गत & 0826251 & A2rMDo- & ORYS \\
\hline 3T & 01001 J781 & Ost 31007 & AJCIES & OAven \\
\hline 37 & Ola $n t$ J7C & 50ล59003510 & CSYAMA & SOREI \\
\hline 31 & Olen JPC & 7 & BAFEA & MAIZE \\
\hline 38 & Olo o I IXAL & . & ASNKBO & PCC \\
\hline 38 & Ole of 3023 & ? & AQVIZNE & PICS \\
\hline 38 & Oleo 1_36.23 & $\div$ & Agnerks & Pics: \\
\hline 39 & Ole a 1 X2A1 & . & AgNizas & PIOS: \\
\hline 30 & Ola of $1.35 A 2$ & - & COPTEO & FCSI \\
\hline 18 & Ola O1 ISAS & - & AENTZII & FICEI \\
\hline 40 & Ole 1 . $40 A 1$ & ARALYORART SEAST1 & DILRCI & ARALY \\
\hline 40 & 0100144002 & At3926960 & QRLIISJ & ARATH \\
\hline 40 & Ole e 1 40A3 & Polien protains Ole of family & BESLLE & MAIZE \\
\hline 40 & $\operatorname{Otan} 1 \mathrm{BQA4}$ & ANALVDKAFT JS5ETI & D7ilzz & ARALY \\
\hline 40 & OLA DI ACAS & A1S2A10SB & DOFLMA & ARATH \\
\hline 40 & Ole of 1001 & 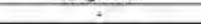 & CETTE2 & SOYBN \\
\hline 40 & Qlest 4063 & ? & c6s215 & soram \\
\hline 40 & Ole 11 do. & . & 87FIO2 & MEDTR \\
\hline 40 & Otea1_408s & POPTRDRAFT_1069266 & B90F61 & POPTR \\
\hline 40 & $010.1+4085$ & POPTRORAFT_TVASYR & B90F5s & POPTR \\
\hline 40 & Olu $=1.4036$ & POPTIDRAFT $5 E 6 E 73$ & AgPAET & POPTR \\
\hline 40 & Ola of 1 AaEl & RCOM_1447040 & BORHIS & Ficco \\
\hline 40 & Oto o 1_40EB & VIT 90013047001 & Drswa & VTM \\
\hline 41 & Olo 21 41A1 & Piclone: DOJlo & Q9L209 & ARATM \\
\hline 42 & Ole o 1 42A1 & At5:13140 & GSFYYI & ARATH \\
\hline 42 & $01001.42 \mathrm{Az}$ & $-\quad$ & QELEU? & ARATH \\
\hline 42 & Otan 1 A2A] & AFALYDKAFT AES1 10 & D7mo72 & ARALY \\
\hline 43 & OAani_ASA & VTISV 01113 B & ASALII & VITV \\
\hline 44 & Ole e 1 पAA & POPTRORAFT Y4172E & g9eMF5 & POPTK \\
\hline 44 & Ole 11481 & Hyarolase & A99kM:88 & R1C00 \\
\hline 44 & $010.1 .4 \mathrm{Cl}$ & POPTRORAFT 45367 I & B9G2CR & POPTR \\
\hline 45 & Ol= el.45A1 & Ep 60 & A5Y538 & EUPPU \\
\hline 46 & 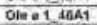 & Oथ 31975 & ESDOCO & ORYSI \\
\hline 46 & Ola of 1 AfAZ & Osalypososizon & ONatis & ONYSH \\
\hline 46 & 010.14600 & 0 . 29955 & B9G4+1 & ORYSA \\
\hline 46 & Olo of $46 \mathrm{AA}$ & 56029029470 & C5K595 & 20NQ1 \\
\hline 46 & $0100146 \mathrm{ABS}$ & 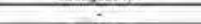 & Ber594 & MALEE \\
\hline 47 & Ole of A7AT & Ost 3825 & ВаврК & ORYSt \\
\hline
\end{tabular}

\begin{tabular}{|c|c|c|c|c|}
\hline 47 & OiA E1 $47 \mathrm{AL}$ & Osi200477890 & D20152 & ORYSA \\
\hline 4 & Obe 1,4181 & - & BAFY⿳⺈ & MAZE \\
\hline 47 & Ol6 01.4782 & - & $8672 W 5$ & MAIZE \\
\hline 47 & O10 $+1,4783$ & so0011s012a40 & GQNRPE & soral \\
\hline 47 & 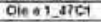 & $=$ & COPAVO & MAIE \\
\hline 41 & OA6 Q1 ABA1 & Povien oie a 1 alergen & OTR2TY & ARALY \\
\hline 48 & $01001,4 \mathrm{BAZ}$ & ATsotot30 dibe protein & Brvosa & CARAS \\
\hline 4II & Dtoet ARAB & Alsg10130 & $296 x+5$ & ARATH \\
\hline $4 \pi$ & OHEA 1 KIAA & Putalive pollen Otu 41 allorgen & CSUS38 & ARAAL \\
\hline $4 \pi$ & OFe $48 \mathrm{BS}$ & SOADE-10 & वसABOन & BRARP \\
\hline 48 & OHE 614881 & - & BSHFNZ & POPTR \\
\hline 48 & Ois of 4882 & - & Eariss3 & POPTK \\
\hline 48 & Ole 61.4683 & Foller-specinc preizin $\mathrm{C} 13$ & EATAHO & RICCO \\
\hline 48 & Oto $91.48 C \mathrm{CH}$ & - & DTMANHS & ARALY \\
\hline 48 & Ole $+1.49 \mathrm{CZ}$ & Allarven dike protioin ERSizo & Q9832 $\sqrt{3}$ & ARATH \\
\hline 48 & Ole et_afCa & Poilea soeciflc protein & 24207 & ARATH \\
\hline 48 & OHe $\because 48 \mathrm{OH}$ & . & A9P9S6 & POPTR \\
\hline 48 & Oine 1,4802 & $=$ & AGPGEO & POAT \\
\hline 48 & $O L=1, A B D 3$ & $=$ & ASPCWZ & POPTK \\
\hline 18 & OHe 1 AROH & 4 & ADPMVI & POPTK \\
\hline 48 & Orea 4805 & Poflen-specific motein cis & BSRDEF & RICCO \\
\hline 48 & Oloat, $A B D 6$ & Pollen-specific proteiry & Q2iad & NicLa \\
\hline 48 & O1601 4807 & $=$ & ASBPK & VTV \\
\hline 48 & Otsol_tedo & scallotd_357 assenbivizx & OTRBA & VTV \\
\hline 48 & $010+1.4609$ & + & EZMAG & CAIPE \\
\hline 48 & Olget 1 _tapia & Allwruendlku protain Bkșinze & OSSESA & SAMNI \\
\hline 48 & Ole 91 A3E! & Pulalive SAHT provivin & OAPKC & COSEA \\
\hline 42 & Ole 1 . 49E & Putalive sant protein. & Q94PK9 & GOSME \\
\hline 42 & 01001.490 & Putalive SAMT? prolelir & C84PKE & cosea \\
\hline $4 \pi$ & Diee1 ABEA & Putalive Sart protein & Q84PK8 & GOSFA \\
\hline 45 & Ole a 1 . ABES & Putdive SAHY prisain & 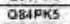 & $605 k 1$ \\
\hline $4 \bar{\pi}$ & Oire of SBFI & $=$ & CESVN7 & SOVEN \\
\hline 48 & Ole o 1 _tap2 & 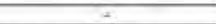 & CESVRS & SOVBN \\
\hline 48 & O16:1,4253 & $=$ & B7FN25 & MEOTR \\
\hline 48 & O1001 4801 & ILP-B3 proigent & geozs2 & $1 / 610$ \\
\hline$\frac{18}{48}$ & 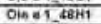 & Hezoginas a prodein & क्षाइड & OAVaA \\
\hline $4 B$ & Ole $01.48 \% 2$ & - & $A 2 \times 522$ & onysi \\
\hline 48 & Ol6a $1.4 \mathrm{BH}$ & 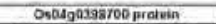 & $07 \times 102$ & ORYSU \\
\hline 42 & Ote 91.4844 & Poitem specific greme protoin & 040715 & ORYSA \\
\hline 42 & Ole o 14245 & 50060014740 & CSYFA3 & SOR日 \\
\hline $4 B$ & Ole $01.48+6$ & Poflem-specific proten c1 & P30050 & SALZE \\
\hline 48 & 0601,4847 & Pollen-spectir protese $\mathrm{CI}$ & BETIAS & MAIZE \\
\hline
\end{tabular}

Table 1. (continued). The Ole e 1 protein superfamily: new and unified nomenclature. 
Systematic and Phylogenetic Analysis

\begin{tabular}{|c|c|c|c|c|}
\hline 48: & Ole ef a ditk8 & . & DAFKO2 & MAIZE \\
\hline 18 & Oig of 1 . 8 HB & Pellen-sgocide protein C13 & вєт7za & MAIZE \\
\hline 48 & Cleot_4sil & Putalivo polten specific prot.c1 1 & QHRUSO & QRVSI \\
\hline 48 & Oe 01.4312 & Os 1090371000 orot ein & Oanys9 & ORYSA \\
\hline 48 & $016 \cdot 1.4813$ & & A2Z615 & ORYS \\
\hline 48 & Dieet_alls & Pollen-spacific protein Cys & B65.4a & MAIZE \\
\hline 48 & Oloot 4ais & Pollian spocific, protebin CIs & B6T594 & MAIZE \\
\hline 18 & Ceo 1_A4I6 & Stootzso14630 & C6गHR2 & SOF日 \\
\hline 48 & Clest AaI7 & Pollunsespectic poisele & OA7lat & HYAOR \\
\hline 49 & Q.e.t.481 & Majar polen silergen Lol p 11 & ama105 & LOLPR \\
\hline 48 & Qreo 1.482 & Pollten slargen Phis o 11 & Q8nGL 7 & PHLPR \\
\hline 48 & 09601.4853 & 50030001020 & $C 5 \times k 36$ & SORBA \\
\hline 48 & 06001.4824 & Polien slergen Phi p 11 & 86 7228 & TAMZE \\
\hline 48 & OWe 1.485 & & A2YET & ORYSI \\
\hline 48 & OKoet_ASNTi & Os06p0556600 proiein & 052710 & ORrs \\
\hline 48 & Ole et_4uKi & 500150007260 & csruva & SOREI \\
\hline 48 & Oles. $48 \mathrm{~K} 2$ & 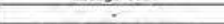 & BAFCCI & MAIZE \\
\hline 46 & $01061.48 \mathrm{KI}$ & Podien aliforgen Poj D 11 & B5tros & TOALEE \\
\hline 48 & 0601.4847 & : & BSBEUE & ORYSI \\
\hline 48 & Ole ef $A 812$ & . & ASCHFG & OKVE \\
\hline 49 & Ote 01 1_486S & $\begin{array}{l}\text { Purativi pollen specinc protoin } \\
\mathrm{Cy3}\end{array}$ & Desoz4 & ORYES \\
\hline 48 & Ote日 IELA & Os08p057280e proteilin & QOZZFO & ORYSI \\
\hline 48 & 0601.4965 & Oso700500500 protein & Q6रLHE. & ORYSI \\
\hline 48 & 01601.4960 & . & A)B(a) & ORYSU \\
\hline te & Olues daLf & . & A2YKail] & ORYSI \\
\hline 48 & Ole 21 , AlECh & 50079012830 & CSXEPI & SOREI \\
\hline 18 & Ole of ASAT & . & ChTos & SOYBK \\
\hline 50 & Ole $1,50 \mathrm{Al}$ & Poflen ole 61 vilergen & D7KVE2 & ARALY \\
\hline 30 & Ole $1,50 \mathrm{DZ}$ & Pollen ole of vilergen & D7kvo8 & ARACY \\
\hline 50 & Ole. 1 SDA3 & P-gixcerate muase 1 bike prot. & QRlous & ARATH \\
\hline 50 & Ole of SIIA4 & . & 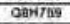 & ARATH \\
\hline 50 & Oloe 1 sons & Poilen specino pratsin & Q42033 & ARATH \\
\hline T1 & Ole o1 StA1 & Frsk19.75 protein & क93Gर 6 & ARATH \\
\hline 52 & Oleof $52 A 4$ & Atto29140 & OBIWDE & ARATH \\
\hline 52 & Ole $5,52 \mathrm{AZ}$ & F23N24.15 protefn & O96 P44 & ARATH \\
\hline 52 & Die 61 15281 & Atsodstata & Q6ล0L3 & ARATH \\
\hline $5 ?$ & Dlo 1.5282 & Ole etthes protein & getsps & ARATH \\
\hline$\frac{13}{32}$ & Ole =1 5265 & . & DTMSOE & ARALY \\
\hline 52 & Olent 5284 & Al4utesas & ONNMMJ2 & ARATH \\
\hline 52 & Ole of szas & Pullen ole of aliergen & DrMCOS & ARALY \\
\hline 52 & 010.15286 & Ole el-like protein & O9F 44 & ARATH \\
\hline
\end{tabular}

\begin{tabular}{|c|c|c|c|c|}
\hline 52 & Ole ot $52 \mathrm{CA}$ & Oient dilk o prathin & OA9613 & QETPM \\
\hline 32 & Olent $52 \mathrm{Dt}$ & Puilen diergen Che a 1 & BSSUAF & FicCO \\
\hline 52 & 010015281 & PNADOZZ & DITJLT & VIM \\
\hline 52 & Ole et $52 \mathrm{Ft}$ & $=$ & $\operatorname{cst} 27$ & SOVEN \\
\hline 52 & 01001,5272 & $=$ & G/FGM & MEDTR \\
\hline 52 & $040.1,5291$ & Polien silergen Che a 1 & QILGRO & CHEI \\
\hline 52 & Q $2 n+1,5702$ & Pollien albergan Cro st & O2sw25 & CROSA \\
\hline 52 & $010.152 \mathrm{HI}$ & Salk/ & E200Z0 & SALKA \\
\hline 52 & Cleo 1 . 221 & 2 & ESN635 & POPTK \\
\hline 52 & $010=1,5212$ & $=$ & EgPyzo & POPTK \\
\hline 52 & Oles: 5212 & ? & Byivi & POPTK \\
\hline 52 & 01001524 & AMther-sbecific Drol LATS? & $8958 \mathrm{k} 9$ & $\mathrm{RACCO}$ \\
\hline 52 & Oln $0152 \mathrm{Kt}$ & Ast & OTROW3 & cosha \\
\hline 52 & Oide el 52L & Anther-spmeints pari- LATS2 & P13447 & $3041 \mathrm{C}$ \\
\hline 53 & Oleot STAA1 & $=$ & DIKDOS & ARALY \\
\hline 54 & O10 01 S4A1 & Pollen-spectific protelin - like & 049527 & ARATM \\
\hline 55 & Ole 01 55A1 & Putative ole of tike protein & AJFAAS & NicLia \\
\hline 36 & D1001 BGA1 & Major polien abergar Pialt & Pe्2262 & PLALA \\
\hline 57 & Dien 01 Th & Aletgen Fra 0.0101 & arxavs & FRAEX \\
\hline 57 & Ole o1 S7AZ & Fra e $100 \mathrm{z}$ majar althrgan & OSEX.J5 & FRAEX \\
\hline 57 & Ole 1 STAL & Major pollen allurgen $L_{g} \vee 1$ & Dखस्मा5 & $\mathrm{LoV}_{\mathrm{in}}$ \\
\hline 51 & Ole 1 I STAd & Otu in 1 alive pollun allerigun & $x 75 \times 98$ & OtHEII \\
\hline $5 \pi$ & Die. $157 A 5$ & Ote 19 ofive pollen diergeir & AF532765 & OIEEU \\
\hline 57 & O1061.57A6 & OHe of ditve poliar allergen & AF532766 & OIOEA \\
\hline 57 & OID $0137 A 7$ & Obe 1 olive politen alierosn & A.512767 & OLEA \\
\hline 57 & Ole ol STAE & 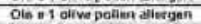 & $x 76336$ & QIUEี \\
\hline 57 & OIIE. $137 A 5$ & Ole e 1 aíw patien alliangen & Prg963 & OLEEIS \\
\hline 5) & OVen_STATO & Ote of alive polien allergen & $\begin{array}{l}\text { Clno } \\
1 \text { Eilman }\end{array}$ & MUEU \\
\hline 57 & Obe + 1 S7AIt & Ote of alive potien allergen & $\times 75585$ & OIEEU \\
\hline 57 & O1001 $57 A 12$ & Oif e 1 sive polion siler gen & K17428 & OIAEU \\
\hline 51 & CBEDI BTAT3 & Oite e I alive politar allergen & राथश & Oineu \\
\hline 57 & Olnet 5TA14 & Oin 11 olive polien alliesgen & AF $50090 \mathrm{a}$ & OtnEI \\
\hline मा & Gent_BTA1E & Dle 11 alive politen allergurn & AFDis277 & OIUEI \\
\hline 5) & Conet BTAIE & Dle a 1 alike poilen allergun & AF $51327 \pi$ & OlQEU \\
\hline 57 & Oe=1 57A77 & Olo of alive polten dilergen & AF515230 & OHER \\
\hline 57 & OFEEI_STAT: & Ote of olive poflen aliergen & AF515273 & DTEEU \\
\hline 57 & Oinel S7A19 & Ole e 1 dive polien alieroen & AFS15zat & OIGEU \\
\hline 5i & OIn 11 STAZO & Ois of $f$ alive poling aliesgen & AF532755 & Oireat \\
\hline 57 & Oin =1. $57 A 21$ & Oie e 1 olizve polier diliergan & AF $93275 \mathrm{Si}$ & OinEA \\
\hline 57 & Olent-B7AZZ & Dte a 1 alive polion altergen & AFDSJE751 & OluEM \\
\hline 57 & OeE $1,57 A 21$ & Ole e 1 olite polien allergen & AF5SIIEO & DIEEU \\
\hline
\end{tabular}

\begin{tabular}{|c|c|c|c|c|}
\hline 57 & Olaes STA24 & Oie of nlive poilen diergen & AV532753 & OAEL \\
\hline 87 & OI0ET_STAZS & OSe of wilvw poflen slergen & AFS327SA & OVEEU \\
\hline 57 & 960157426 & Ote e 1 vilive pallen altergen & AYr137467 & बबहू \\
\hline 57 & 0160157420 & Olo o 1 otive pellen intergen & AYt3746II & GIeEI \\
\hline 67 & Cient_57A29 & Gie of dive pelien allergen & AY137469 & GEEU \\
\hline 87 & OIEOS STANO & Oib of doliva politen alergen & 575766 & GIELU \\
\hline 57 & Oleat I J7ASt & Ole e 1 culive pesilen allergen & V12426 & DQEU \\
\hline 51 & OIE- 1 SIAN2 & Ote of nlive pallen allergen & AF532752 & CloEu \\
\hline 57 & OVe 1 1 $57 \mathrm{AOS}$ & Ote 91 oflive pollen altergen. & Af532761 & OH०En \\
\hline 57 & deo, stays & Ote of ofim polfen alergen & AF532762 & QUEU \\
\hline 57 & Geen_staus & 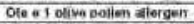 & AF532759 & Q GeEu \\
\hline 57 & DIOE 157436 & Oie ef alive puilen slergen & Af532764 & OAEU \\
\hline 57 & OLon $1,57 A 37$ & Oie n 1 wive pallon slergen & AF532763 & OIDEU \\
\hline 57 & Oloot_Gtajil & Ole of țilve pallew Elergen & AY1BDEE & OIDEu \\
\hline 57 & O16e1 57A39 & Ote e 1 olive pallen altergen & AY151889 & C)E्I \\
\hline 57 & 01e01_574a0 & Aleorgen fraed & Q6U740 & FraEx \\
\hline 57 & Oleol S7AA1 & Olo e 1 dive pellen aliorgen & $x / 6541$ & GIEEU \\
\hline 57 & Gear S7AA2 & Gin at wive peillent allergen & $x>6540$ & COEEI \\
\hline 57 & 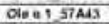 & Ole a 1 divivi polien allergen & $x 76533$ & CloEI \\
\hline St & DEO O 1 SAAT & 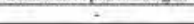 & BTFNFS & MEOTK \\
\hline 5u & 01001,5842 & . & BIFNF3 & MEDTR \\
\hline 5i & 01001 58E & . & CESYES & soran \\
\hline 59 & 010015921 & Extensiniकiकn protein & AQMWMRE & PiCG \\
\hline 69 & 01001.5942 & 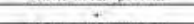 & A9NipL2 & PICS: \\
\hline 59 & Oitre 15943 & Exiensiobikn pratein & EOZEE2 & PICS \\
\hline 55 & Ole E 1_S9AG & Extensiotike preifein & EAZEDO & PICS \\
\hline 59 & DIe Q1.92AS & Exlensintike prutein & Eazera & FICI: \\
\hline 50 & O1001.600A & ATIg2700/7TN 15 & OMAES & ARATH \\
\hline EO & Ole $+1.50 \mathrm{Az}$ & 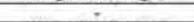 & Q:L1722 & ARATH \\
\hline 50 & 010.1 .6023 & Pollen ole o 1 allergen & олы्र: & ARALY \\
\hline 80 & Qloet $150 \mathrm{AS}$ & 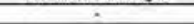 & C6svor & SOYEN \\
\hline 60 & Oin e1, 60.55 & - & Co5Ta74 & SOYEN \\
\hline EO & D10. $1.60 A 6$ & - & AQPBAO & POPTR \\
\hline 50 & 010016007 & - & ASPFLI & POPTK \\
\hline 60 & D1001,604I & - & B2SAF & RICSO \\
\hline 60 & Oine 61,6029 & Prsangat & DThe95 & VTM \\
\hline 60 & doet 00410 & - & $A 2 \times 417$ & ORYS! \\
\hline BO & Oloot E0A11 & Os02002517mo0 protsin & $062 \times 41$ & OAVW \\
\hline 60 & Moel Sha12 & 50070009530 & c5YsW & हORब \\
\hline E0 & O6001 G0213 & 5 & BOTA4 & MAIZE \\
\hline 50 & Obe.1.605t & t. & BELAFI & Pics \\
\hline 61 & 01001.6341 & & DBRWGS & ARATH \\
\hline
\end{tabular}

\begin{tabular}{|c|c|c|c|c|}
\hline 61 & OLe $0161 A^{2}$ & Ne2g16ธ30 & OSLT4 & ARATK \\
\hline 61 & 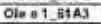 & $\div$ & D/L7M3 & ARALY \\
\hline 51 & Dle 01.6101 & $\div$ & 89स158 & POPTR \\
\hline 51 & 01601.6982 & . & A.PPQ40 & POPTR \\
\hline 51 & 0401 6183 & $=$ & E95a/5 & Aicco \\
\hline 61 & 04016184 & & 070593 & VIN \\
\hline 62 & Die 81 . 62A1 & PNALOCZA & AZWZES & OEYS: \\
\hline 52 & Ole el_fizAZ & . & AIAZSS & DRYS \\
\hline 52 & Ole =1 B281 & - & 861727 & MAIZE \\
\hline 62 & 0601.6202 & - & BSFZU6 & MALEE \\
\hline 52 & 04061,6283 & . & BETRI2 & MAIZE \\
\hline 63 & Oin 01 . B3A1 &. & EGUFCO & MAZZE \\
\hline 64 & Oln $81,64 A 1$ & 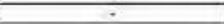 & ASRO1S & PHYAA \\
\hline 54 & Olo Q 1.6A日 & - & A9SHUD & PHYPA \\
\hline 55 & Ole o 1 BSA & - & DRTAVE & SELML \\
\hline 55 & $06001,65 A 2$ & - & Dertops & SELML \\
\hline 56 & $04001.66 \mathrm{AT}$ & . & ormyzo & ARALY \\
\hline 65 & Oir $\triangle 1.65 A 2$ & praine-rich Giycupgrelein & 064585 & ARATH \\
\hline 6क & OLE Q 1 BEAJ & - & D7LN37 & ARALY \\
\hline 57 & Dlo $01,67 \mathrm{AT}$ & - & DTLGE & ARALY \\
\hline 67 & $0669.67 \times 2$ & A12g33790 & pg3013 & ARATH \\
\hline का & Dion 1.6781 & Al1gZ2200 & QQAZZAZ & ARATH \\
\hline 57 & 0601.6782 & proting-rich protein & OOWP47 & ARATH \\
\hline 57 & 04061.6783 & 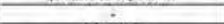 & olkcue & ARALY \\
\hline 67 & $0601.67 C 1$ & HYPRPT & COPIW' & GOSHI \\
\hline 67 & Olu 81,6701 & Arabinegalacten protein & CEYOU7 & Goshl \\
\hline 68 & OLEO $1,6 B A 1$ & 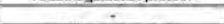 & C6TLD2 & SOVEN \\
\hline 68 & Ole e 1 .0BAZ & Drofimerich protein & Q41122 & PMAVU \\
\hline 68 & 01601 6881 & . & B7ค53 & MEOTR \\
\hline 58 & OHe $1.6 \mathrm{ECT}$ & . & ASPAWS & POPTR \\
\hline 68 & 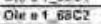 & . & AGPAA2 & POPTR \\
\hline 68 & OLe a 1 BisOT & $=$ & E9N307 & POPTR \\
\hline 68 & Ole o $1,6 \mathrm{BDO} 2$ &. & вยหzтง & POPTR \\
\hline 68 & 06661,6903 & . & Allpes & POPIR \\
\hline 68 & Dion t_batet & $\begin{array}{l}\text { Eituelurai cuestituent of tail } \\
\text { welt }\end{array}$ & gisaces & ficco \\
\hline 58 & Ge 01 हान & PNAOOR2A & DITGE & VTV \\
\hline 68 & Oinet. 6301 & Ar chingegalacten proenin & OgesW & DALUCA \\
\hline 69 & OLE $=1$, A3A1 & Tyborict pistlinw-rich protein PRPI & $09 \times 558$ & Trist \\
\hline 70 & Ole e $1,70 \mathrm{A1}$ & Proline-rich protoin & c07u84 & NICAL \\
\hline 70 & $01601.70 A 2$ & 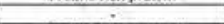 & colis3 & PETHY \\
\hline 70 & $0,0,1,7009$ & Praline-rich propein 1 & Q6ONAS & CAPAल \\
\hline
\end{tabular}

Table 1. (continued). The Ole e 1 protein superfamily: new and unified nomenclature. 


\begin{tabular}{|c|c|c|c|c|}
\hline 71 & OLE OI TBAT & Pissil extensindites procein & orasis & RECAL \\
\hline 71 & Olon 1, 11A2 & Fisill-specific axiansin dikg prot. & 003217 & PEXLP \\
\hline$\pi$ & 0601.7181 & Pistil extensin liko protein & Q4054! & TOEAC \\
\hline$\pi$ & Ote 21.7181 & Pistlf extensin flike protein & 040552 & TOEAC \\
\hline 72 & Ole $01,72 A 1$ & 120 hoa stye givcoprotein & 042956 & BAICAL \\
\hline 72 & O6001_RAZ & 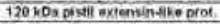 & Ot:्र28 & Nicla \\
\hline 72 & Ole e 1 1203 & $120 \mathrm{kDa}$ plstif exlenstin dike prat & 049428 & Nicla \\
\hline 72 & O6n:1,72A4 & $170 \mathrm{hDa}$ pistil entersing dike prot. & OAxy & Nicta \\
\hline 72 & Olw $01,12 \mathrm{AS}$ & $120 \mathrm{nD}$ a pistli entensin-like prot. & 045932 & NicLa \\
\hline 72 & $01001,72 A G$ & $120 \mathrm{kDa}$ piseli extersin fike prol. & O4ST33 & NICPL \\
\hline 72 & OK0 Q1 72A7 & $120 \mathrm{kDa}$ pisill exterishe tike prol. & 0.914 & TOBAC \\
\hline$D$ & $01001.73 A 1$ & $120 v 0 \times$ piali extemsinsthe prot. & 201930 & Nicha \\
\hline 74 & OLEOT $74 A \mathrm{~A}$ & Pollan bie of delergen & Oralize & AKALY \\
\hline 74 & OLS $Q 1,7 A A 2$ & Astuozzio & Oa1417 & ARATH \\
\hline 75 & Ote $81,75 A 1$ & 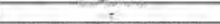 & CETSTI & SOYBN \\
\hline 75 & Ole $41.75 \mathrm{A2}$ & Draoght resistance protainf & EOAZ2S & Soran \\
\hline 75 & $0160175 \mathrm{~A}$ & $=$ & C8T225 & SOYAN \\
\hline 75 & O40 01_ग8ब1 & - & BSEP3 & POPTR \\
\hline 75 & 0609.7582 & $=$ & BMgP2 & POPTR \\
\hline 75 & Oles $175 \mathrm{CT}$ & $=$ & $\operatorname{Bgan} \times 40$ & POPTR \\
\hline 75 & Obon1.7SC2 & ? & B9PS57 & POFTK \\
\hline 75 & Ote a 17501 & . & E9GSD2 & POPTK \\
\hline $7 \mathrm{rin}$ & $0601,76 A 1$ & - & B9SAVB & RICCO \\
\hline 76 & Ote o 1,7681 & 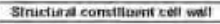 & BUSAVA & BICCD \\
\hline$\pi$ & OFOQ977RA & $\because$ & B9OSDA & POPTR \\
\hline$n$ & O60.1_TTA2 & Strueture cofsituent colil wall & B:SAV3 & RICCO \\
\hline$\pi$ & Olo 01.7781 & PNaC0024 & D7ures & VIT \\
\hline 77 & Olm 81,7782 & 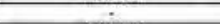 & ASE1Z7 & VITM \\
\hline$\pi$ & 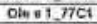 & PNA0024 & DTuze.3 & VIM \\
\hline$n$ & Ole $0177 \mathrm{C2}$ & 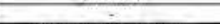 & A5E12.5 & VIM \\
\hline 77 & 01601,7701 & Poilten ale e 1 visergen & DTLQP2 & ARALY \\
\hline$\pi$ & 01601,7702 & AtrodissD & 072257 & ARATH \\
\hline 79 & OLS O I JEAT & . & A5E126 & VIM \\
\hline $7 \pi$ & Ole $01,7 B A 2$ & PHADOZ24 & DruzeA & VITM \\
\hline 75 & Obe $61,73 A 1$ & - & $071 \times 021$ & ARALYY \\
\hline 74 & O10.1,79AZ & - & $07 K 024$ & ARALY \\
\hline 74 & Ole $11,79 \mathrm{AZ}$ & Proline-rich protein 1 & 091235 & ARATM \\
\hline 70 & $01001.79 A_{4}$ & Prolieno-rich arotein 1 & Qimulp1 & ARATH \\
\hline$T 9$ & 01007.7925 & Proline-rich pratein & 9प्रम7 & ARATH \\
\hline 79 & OBD O I 7206 & Prolina-rich protelin 3 & Qgarates & ARATH \\
\hline 75 & OWM $1,75 A 7$ & ? & D7LTa & ARALY \\
\hline Bin & OHE 61 BOA1 & . & DILPO & ARALY \\
\hline
\end{tabular}

\begin{tabular}{|c|c|c|c|c|}
\hline Ea & OLS e $180 A 2$ & . & 022258 & AAATH \\
\hline E1 & Ole 81 B B A & . & DETCEE & SELML \\
\hline 91 & OWO 1 B1A2 & ? & DETF4: & setant \\
\hline $8 t$ & Ote 218181 & - & DATCET & SELMML \\
\hline 07 & O1601.92A1 & ? & DBTCFO & SELML \\
\hline 83 & OHO 01 .83AT & Politer ole of 1 asergen & $0 \pi \sqrt{x} \times$ & ARALY \\
\hline 83 & Oine 1 BSA2 & Ar5g05500 & DSFFES & AHATH \\
\hline 83 & Dla 01 . 1381 & 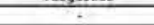 & BOHHU & POFTK \\
\hline 183 & Ole 01 1 B382 & ? & BSHSK7 & POPTK \\
\hline 83 & 0669.8383 & - & DESGRE & बicco \\
\hline 83 & Obees g3B4 & PN40024 & DITAL1 & ทTM \\
\hline 63 & 01001.8385 & . & AScavin & VITM \\
\hline 84 & Ole of $18 A A$ & . & ATWLOS & onYsi \\
\hline in & OIS $Q 1$ BAA2 & ? & OSLIN2 & OaYs. \\
\hline in & Ola o : B BA.3 & $?$ & AZWLDOT & onvsi \\
\hline 酷 & Ole Q1 BAA4 & . & В9อTV & OAvs \\
\hline 84 & Ote a 1 SaAs & B1139A09.32 & OSVR3? & ORVS \\
\hline कि & 01001 शिम & ? & A2WLOOO & OबYज्ञ \\
\hline 8 & OLE C 1 BAA & . & A2WLOS & oays \\
\hline (3it & ole 11 BaAn & . & AZWLOS & ONVB! \\
\hline$\frac{5}{64}$ & Oto. 1 BAAS & 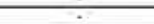 & QRLIMI & ofrsi \\
\hline BA & OLPEI SAA1D & . & AZWLD? & OKYSt \\
\hline 54 & OQOOI BAA1T & ? & OFL.JMB & ORYs \\
\hline 5i & OCOE, SAA1Z & $\Xi$ & AZWLOA & OKYSI \\
\hline 84 & OCe0.1.5AT12 & . & oflam 3 & ORYS \\
\hline 84 & Ofe O MA14 & I & A22PKK & ORYSS \\
\hline की & dent ask15 & вท8 & Q5VF30 & ORYS \\
\hline B4 & Ota o 1.8481 & $=$ & ATWL02 & ORVSi \\
\hline Bit & Ois of BAC1 & , & A2WL12 & OAYSI \\
\hline 94 & Oto o 1 \& $84 C 2$ & - & ORLJTes & ORYS \\
\hline 94 & Ol6 01 g4C1 & ? & BDADEY & ORYSI \\
\hline 84 & OHe o1 gACA & ? & AZZPL 3 & ORYS \\
\hline 84 & Oin e1 \&ACS & E1789a09.42 & Q5VR? & ORYS \\
\hline at & Ole 11 в 4 C & . & AzWLL11 & OKVS! \\
\hline 84 & Ole of $84 \mathrm{CT}$ & . & 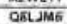 & ORYSI \\
\hline क्ष & Olo 918401 & 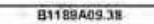 & OSVR-19 & ORYS \\
\hline B4 & OLED 1 SAEI & ? & Baetos & ORYS \\
\hline 54 & Olo 11 PAf & . & AZZPLE & ORYE \\
\hline 84 & Q & E11a9A09.45 & QSVR1 & OAYSS \\
\hline 34 & Ole 1 I बमन & . & A2WL13 & onysi \\
\hline 84 & Oise : I 5462 & sboxg005060 & CSXP49 & SORBi \\
\hline as & OLD A 1 BSA & . & DBSHHE & SELLML \\
\hline
\end{tabular}

\begin{tabular}{|c|c|c|c|c|}
\hline 95 & Ole o 1 .8581 & 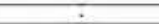 & DSTSS3 & SELML \\
\hline 86 & OLOQ1 SSAT & . & DESHAT & SELML \\
\hline 87 & OHE 1 187A & - & $08 T 554$ & SELGLL \\
\hline 8 & Oln o1 BaAt & . & DBRAES & SELML \\
\hline $8 \pi$ & Ole $61, B A A_{2}$ & . & D6RKG & SELML \\
\hline 89 & Ole $E 1$ SBAT & Pulfen ofe e 1 allergate & DTLEEA & ARALY \\
\hline 89 & Ode of $89 A 2$ & . & ajeBa? & ARATH \\
\hline 89 & Olae 1 gab1 & $=$ & B9MTKS & POPTR \\
\hline 89 & OPe 61 as 292 & $=$ & 895087 & RicCO \\
\hline 89 & $0106189 \mathrm{CH}$ & $=$ & CETrut & SOYBN \\
\hline 90 & Oin of gotat & PNADOD2A & ortaw: & VITV \\
\hline 90 & Ote $61,90 A 2$ & PNACO24 & DrmXt & nTn \\
\hline 91 & Ole of_BAA & . & A2Z9X7 & OAYSI \\
\hline 91 & Olest B1A2 & 0 S10005:6100 & osavi & DRYSU \\
\hline 91 & Oto-1381 & sborgosoago. & CSWTRi & SORBi \\
\hline 92 & Oin 61 92A) & 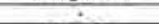 & OTLFBS & ARALV \\
\hline 92 & Oln ${ }_{1} 192 \mathrm{A2}$ & A42045400 & OSOEF & ARATH \\
\hline 92 & OLe 81 B B2A. & FAF $[27 \leq 13+412$ & बकाचा & ARATH \\
\hline 92 & Olue 1 . 3281 & Alzol1400 & OAIZVCD & ARATH \\
\hline 92 & Ole of 9281 & Al2041390 & OSZVCA & ARATH \\
\hline 93 & O10 of . 934 & A15005020 & O9FF/2 & ARATH \\
\hline 94 & OAe $=1$ gtA & 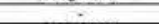 & DrkW90 & ARALY \\
\hline 95 & OIA E 1 . BSA & As3gt66 & QROYY & ARATH \\
\hline 95 & Oin $61,95 \mathrm{AZ}$ & MGLK & Qूपनि: & ARATH \\
\hline 95 & $04=01,95 A 3$ & . & $D 76657$ & ARALY \\
\hline 95 & Ole of 19581 & - & D7L658 & ARALY \\
\hline 95 & Olo e1 9582 & AT3916570MOLE 12 & QILURE & ARATH \\
\hline 95 & 0601 96C1 & I & BSHXTS & POPTR \\
\hline gs & $04061,95 \mathrm{C2}$ & 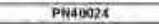 & Disros & VITM \\
\hline DS & Olent $05 \mathrm{CS}$ & Phyloplasin & $890 \pi 72$ & RICCO \\
\hline 95 & Olo $P 1$. & 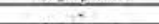 & СबTKББ & 50VBt \\
\hline 95 & ChOD 1 JSET & Phylilopianin & 056559 & PHYLL \\
\hline 95 & Ole e1 DSF & Phytiopianin & AIPCF? & TOBAC \\
\hline 96 & Ole 61 . 5 SA & - & QSAPES & ORYS \\
\hline 96 & O16 $6195 \mathrm{gS2}$ & - & ब9FBEI & ORYSI \\
\hline D16 & 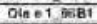 & $=$ & A2 VFFU & ORYSI \\
\hline 96 & Oinet 酸 2 & Os0700674400 protedin & Q6ZDWB & ORYSN \\
\hline ye & Ote o 1 958s & sb02g042710 & C5x513 & उ०R日 \\
\hline 96 & Dle of DEBA & . & BAFFSII & MAIZE \\
\hline 96 & Olee 1 gses & Sourgursary 0 & $65 \times 000$ & SORES \\
\hline 97 & 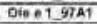 & 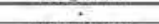 & A2YPVS & OAYS \\
\hline 97 & Oine1 $97 \mathrm{AZ}$ & 0,0700674500 & $0620 w 77$ & ORYS. \\
\hline
\end{tabular}

\begin{tabular}{|c|c|c|c|c|}
\hline 9? & Otoel 97AI & $56029042 / 40$ & $\operatorname{cs} \times 5 \mathrm{No}$ & SOREI \\
\hline 98 & $0601188 A 1$ & - & A2xOI & ORYS \\
\hline 98 & Ole o1 $98 \overline{1}$ & $=$ & ancina & ORYS \\
\hline 98 & Oiest, 9801 & - & $A 2 \times 6, j 8$ & ORYSI \\
\hline 98 & Olont .98dz & Os03y0312100 & O10LN2 & ORYS \\
\hline 98 & Olant_sact & $56010035 \leqslant 30$ & $\mathrm{C5} \times 002$ & 5OFE \\
\hline 99 & Oto e1, ygAt & - & BEUHTS & MAIZE \\
\hline 100 & 91001 100A1 & $=$ & AZWUN2 & ORY \\
\hline 100 & $01601,100 / 2$ & 050100725900 & 085158 & ORYS \\
\hline 100 & Ole D.1_100A3 & 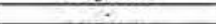 & $A 2 Z \times F=1$ & ORYSA \\
\hline 100 & Oleot 1000AS & Sb0دg037350 & CSXIF5 & SORE: \\
\hline 100 & Ota e 1 1 10061 & Sbo3gaj3360 & CIXIFE & SOREI \\
\hline 100 & Olev1 100C1 & जाls: ह00.17 & Q75K53 & ORYE \\
\hline 100 & Oie $1,100<2$ & $=$ & B9FH39 & ORYS \\
\hline 100 & 0100110003 & $\div$ & A2VET & ORYSI \\
\hline 100 & Oent 10004 & ON0500531900 prothin & Q0DGH6 & ORYSI \\
\hline 100 & Oleet 10001 & Steggozossto & CSYUFE & SOREI \\
\hline 100 & Olent 10002 & Ar datunogatiatian preivin & B6SLV3 & MAIZE \\
\hline 101 & Ole D1_101A1 & 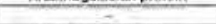 & AZYETA & ORYS \\
\hline 109 & Ole e 1.10192 & Os05005j1200 protein & $075 \mathrm{k} 55$ & ORYS \\
\hline 101 & Ote 01.10189 & 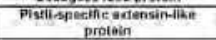 & Besurta & MAIZE \\
\hline 107 & O6001,10182 & - & BAFGK8 & MAIZE \\
\hline 101 & Olent 10033 & Sbegogarisoo & $\mathrm{CSZTHS}$ & SOREI \\
\hline 102 & Ole日1_102AT & - & A2WUN3 & ORYSI \\
\hline 102 & Ole 01 102A2 & Ox0100725100 protoin & QSS154 & ORYS \\
\hline 102 & Oie 61,10281 & 56039032370 & c5xof & SORBA \\
\hline 102 & 0960110287 & Pistillespecific actens in like prot. & BEUHES & MAIZE \\
\hline 103 & 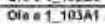 & 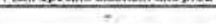 & DBRZLI & SELVI \\
\hline 104 & Ole e t towat & 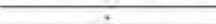 & BAFMCB & MAIZE \\
\hline 105 & Oleet 1 105AT & $=$ & $\mathrm{D} 3 \mathrm{RCL}$ & SELML \\
\hline 106 & Oleot TDOAS & - & $\mathrm{D} 8 \mathrm{~T} \times 05$ & SELML \\
\hline 107 & 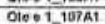 & $=$ & Assc13 & PHYPA \\
\hline 102 & Olec1 Loses & $=$ & DBQYE & SELML \\
\hline 109 & Oleot 100A1 & - & $0895 \mathrm{VE}$ & SELIML \\
\hline
\end{tabular}

Table 1. (continued). The Ole e 1 protein superfamily: new and unified nomenclature. 


\subsection{Phylogenetic analysis of the extended Ole e 1 protein families}

A member of each retrieved full-length Ole e 1 sequences family was aligned to determine phylogenetic relationships within the Ole e 1 extended family. A phylogenetic tree of the Ole e 1 extended sequences is depicted in Figure 1.

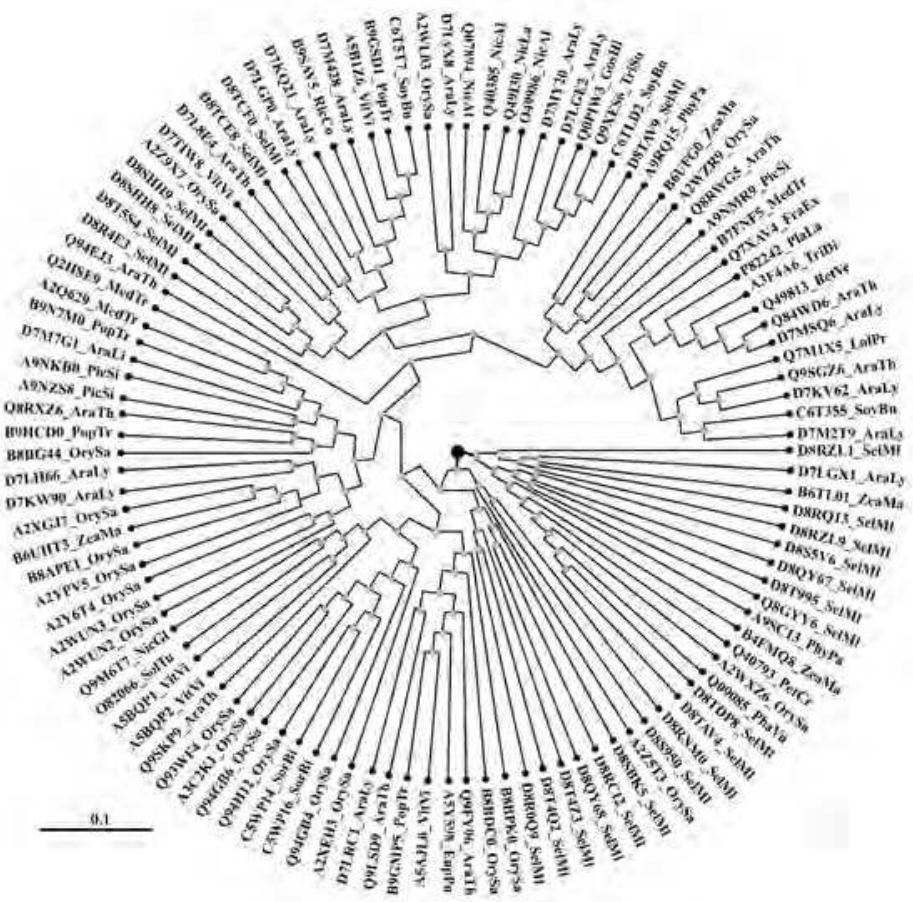

Fig. 1. Phylogenetic analysis of plant Ole e 1 proteins. Neighbour-Joining (NJ) method was used to perform a phylogenetic analysis of Ole e 1 proteins from 109 families. One representative sequence of each family was used, based in its higher consensus ability. Plant species analyzed included Arabidopsis, poplar, rice, spikemoss, tobacco, maize, potato, grape, Sorghum, kidney bean, barrel medic, Pinus, poinsettia, perennial ryegrass, soybean, white birch, ash, Platanus, Physcomitrella, cotton, subterranean clover, Persian tobacco and castor bean.

The phylogenetic tree shows that the 109 Ole e 1 extended families, although highly divergent, are split into two clades. The smaller clade was integrated by a few species like Selaginella moellendorffii, Arabidopsis and maize among others. The second clade included the majority of the Ole e 1 family proteins, clustering together almost all the biological functions (Figure 1). Numerous branches aroused from this clade.

\subsection{Ole e 1 protein superfamilies: Structural and conformational variability}

The crystallographic structural coordinates of relatively few proteins of the Ole e 1 family have been deposited in the Protein Database (PDB) up to date. To our knowledge, detailed comparative studies of the structural and conformational features of members of the Ole e 1 
extended protein families have not been performed in higher plants. Using computational modelling analysis, we have determined and modelled the molecular-structural features of selected members of the Ole e 1 extended families. A first overview of the generated models (Figure 2) indicated a relatively high level of similitude.

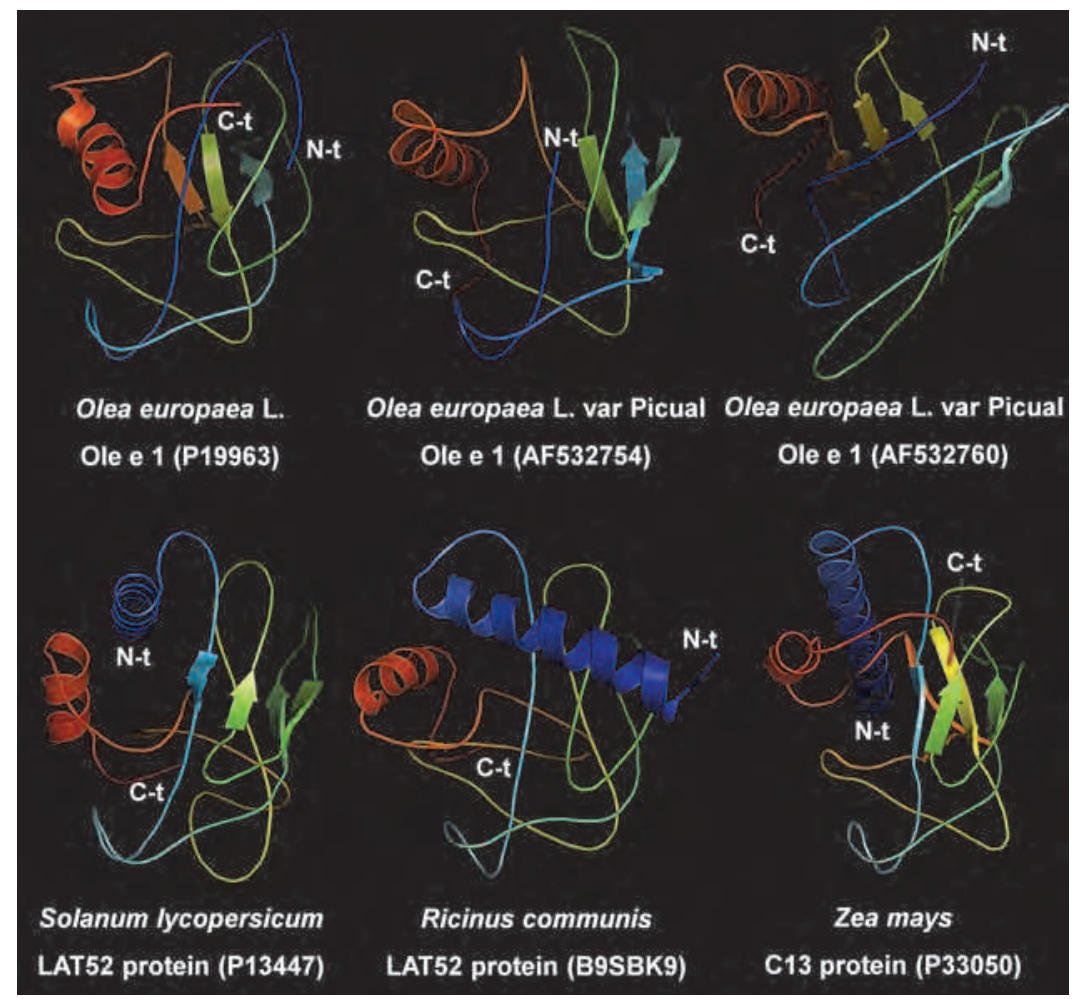

Fig. 2. Three-dimensional structure analysis of selected members of Ole e 1 family proteins. The model proteins are depicted as cartoon diagrams. The secondary elements of the crystallographic structures are rainbow coloured, with $\mathrm{N}$-terminus in blue, and C-terminus in red.

However, a more detailed analysis allowed identifying certain differences in the generated models, particularly consisting in 2D structural features. These differences can be distinguished even between very close proteins like P19963, AF532754 and AF532760 (Ole e 1_57A9, Ole e 1_57A25 and Ole e 1_57A23 with the new nomenclature), corresponding to the olive pollen major allergen cloned from different varietal sources or even to different clones of the same cultivar (Figure 2). The differences become higher when models of the same protein obtained from different plant species are compared. This is the case of P13447 and B9SBK9 (Ole e 1_52L1 and Ole e 1_52J1), which correspond to the LAT52 gene product in tomato and Ricinus, respectively (Figure 2). Divergences are even more obvious between the models indicated above and that of a P33050 (Ole e 1_48H6), a different member of the Ole e 1 superfamily corresponding to a pollen protein from maize (C13 protein) (Figure 2). 


\section{Discussion}

Research as regard to the proteins of the Ole e 1 family has been carried out steadily since its definition. At present, many genes from the allergen Ole e 1 family of proteins have been characterized, and data are available concerning the sequence, structure, expression and biological function (e.g. extensin-like proteins constituting part of the cell wall). However, and as depicted in this chapter, the precise identification of more than half members of this family remains uncompleted. Up to now, Ole e 1 and Ole e 1-like genes are deposited into the databases, many of them with repetitive or arbitrary naming system by authors. This nomenclature includes a variety of generic names, such as Ole e 1 major olive pollen allergen, putative Ole e 1-like protein, anther-specific Ole e 1-like protein, and others depending of the protein location in the chromosome, e.g. At3g26960, Os09g0508200, or simply giving a random name e.g. P1 clone: MOJ10. For those members of the Ole e 1 family which have been recognized like allergens, a more sustainable and precise nomenclature has been built, by following the recommendations of the International Union of Immunological Societies (IUIS) (http://www.allergen.org/ ). However, these allergenic proteins only represent a part of the members of the Ole e 1 family, and this nomenclature still does not display the relationships among these proteins. In several cases, it is still common for researchers to use different names for the same allergen. Allergen biochemistry is now entering a new time of structural biology and proteomics that will require sophisticated tools for data processing and bioinformatics, and might require further definition of the nomenclature. Increasingly, the wealth of structural information is enabling the biologic function of allergens to be established and the assignment of allergen function to diverse protein families. Therefore, the arbitrary nomenclature currently in use is not sustainable for adequate comparative mega-functional genomics studies, especially as the number of Ole e 1 genes has increased steadily and will continue with this upward trend with the completion of the sequencing projects corresponding to more plant genomes.

The implementation of modifications in the nomenclature as proposed here may assist further developments of allergy understanding and new clinical approaches. As an example, nomenclature and structural biology have been proposed to play a crucial role in defining allergens for research studies and for the development of new clinical products [Chapman et al. 2007]. Sequence comparisons and assignments to protein families provide a molecular basis for clinical cross-reactions between food, pollen, and latex allergens that give rise to oral allergy syndromes [Wagner et al. 2002, Scheiner et al. 2004, van Ree 2004]. For food and pollen allergens, intrinsic protein structure probably plays an important role in determining allergenicity by conferring, for example, heat stability or resistance to digestion in the digestive tract, e.g. storage proteins from seed/nuts or legumes [Orruño and Morgan 2011]. Interestingly, analysis of databases, e.g. pFAM shows that there are currently more than 120 molecular architectures that are responsible for eliciting IgE responses. It will be important to link nomenclature with classification of allergens into protein families and subfamilies to provide complete definition of allergens and their structure-functional relationships as part of a comprehensive bioinformatics database. The practical consequences of this approach are seen most clearly with genetically modified foods, in which sequence comparisons can be used for safety assessment of genetically modified organisms [Goodman and Tetteh 2011].

The success of our new and unified nomenclature lies in its simplicity, with genetic basis and structural-functional characterizations of the proteins, regardless of the species origin, 
with the possibility to further nomenclature expansion, to include as-yet-unidentified protein allergens from different sources or species: mites, insects, pollens, molds and foods. It might be also possible to include in the system engineered protein molecules, such as hypoallergens, or others being described as non-protein allergens. Allergens entered into the nomenclature could be used to develop allergen-specific diagnostics and to formulate recombinant allergen vaccines that will benefit patients [Chapman et al. 2000, Ferreira et al. 2004, Jutel et al. 2005, Sastre 2010].

The proposed system may also assist to clarify the importance of allergen polymorphism. Allergens often display numerous variants. These are proteins with typically greater than $90 \%$ sequence identity, but with enough differences in their amino acid sequences to make worth individual structural and or functional characterization and identification. This polymorphism has been deeply analyzed in mites, as their allergens present an extensive number of isoforms: 23 for Der p 1 and 13 for Der p 2 [Smith et al. 2001, Smith et al. 2001]. Furthermore, these polymorphisms might affect T-cell responses or alter antibody-binding sites. These differences can be structurally characterized to distinguish isoforms in a welldefined nomenclature system, by mean of structural-functional differentiation, helping to design allergen formulations for immunotherapy [Jutel et al. 2005, Piboonpocanun et al. 2006]. In the case of pollen allergens, Ole e 1 from olive pollen is a clear example of extreme polymorphism, both in its peptide and in its carbohydrate moieties, as demonstrated by peptide mapping and $\mathrm{N}$-glycopeptide analysis [Castro et al. 2010]. Olive cultivar origin is a major cause of polymorphism for Ole e 1 pollen allergen [Hamman-Khalifa et al. 2008, Castro et al. 2010]. The olive tree has an extremely wide germplasm, with over 1200 varieties cultivated over the world [Bartolini et al. 1994]. Therefore, the number of Ole e 1 isoforms yet to be characterized in olive pollen is expected to be enormous. A similar situation is also likely to occur in many other plant species.

Overall, our developed unified nomenclature system is helpful in a quick functional prediction of any newly cloned Ole e 1 gene(s), because from the nomenclature point of view, the newly sequenced gene(s) will always be characterized/named with sequence similarity with previously characterized Ole e 1 genes/proteins, as well as a protein structure-functional characterization and comparison. The changes that have been introduced reflect into which extended family or subfamily a certain Ole e 1 protein belongs. Accordingly, the new nomenclature will have no significant impact on already published data with old/arbitrary naming system. However, we urge scientists working on Ole e 1's to adopt this new and easy nomenclature system. In this regard, we have made an effort to preserve the user friendly linkage between the old and the new designations, which we hope will help researchers to adapt the new names. As the revised nomenclature should facilitate communication and understanding within the community interested in Ole e 1 allergen proteins, we advocate that this new naming system be used in all future studies.

The classification model used here has been developed under the basis of a previously designed gene nomenclature model for male fertility restorer $(\mathrm{RF})$ proteins in higher plants [Kotchoni et al. 2010]. The increasing numbers of RF genes described in the literature represented an ongoing challenge in their clear identification and logical classification which was solved using the proposed nomenclature. Undoubtedly, similar approaches could be applied to numerous protein families involving relevant levels of nomenclature heterogeneity, many of them registered in specialized databases like pFam. In the case of allergens, other numerous protein families like profilins (Ole e 2 in the case of olive pollen) 
prolamins, cupins, Bet v 1-related proteins etc., which are currently included in the AllFam database [Radauer et al. 2008] (http://www.meduniwien.ac.at/allergens/allfam/ ) could benefit of the use of similar approaches.

\section{Conclusion}

We propose for first time a unified naming system for Ole e 1-like genes and pseudogenes across all plant species, which accommodates the numerous sequences already deposited in several databases, offering the needed flexibility to incorporate additional Ole e 1-like proteins as they become available. Additionally, we provide an analysis of the phylogenetic relationships displayed by the members of the Ole e 1-like family and use computational protein modelling to determine structural features of selected members of this family. These data are of particular relevance for the understanding of their biological activity and allergenic cross-reactivity.

\section{Acknowledgment}

Support of the Spanish Ministry of Science and Innovation (ERDF-cofinanced project BFU2008-00629) and Andalusian Regional Government (ERDF-cofinanced Proyectos de Excelencia CVI5767 and AGR6274) is gratefully acknowledged.

\section{References}

Alché, J.D.; Castro, A.J.; Olmedilla, A.; Fernández, M.C.; Rodríguez, R.; Villalba, M. and Rodríguez-García, M.I. (1999). The major olive pollen allergen (Ole e I) shows both gametophytic and sporophytic expression during anther development, and its synthesis and storage takes place in the RER. Journal of Cell Science, Vol.112, pp.2501-2509

Alché, J.D.; M'rani-Alaoui, M.; Castro, A.J. and Rodríguez-García, M.I. (2004). Ole e 1, the major allergen from olive (Olea europaea L.) pollen, increases its expression and is released to the culture medium during in vitro germination. Plant Cell Physiology, Vol.45, pp.1149-1157

Altschul, S.F.; Gish, W.; Miller, W.; Myers, E.W. and Lipman, D.J. (1990). Basic local alignment search tool. Journal of Molecular Biology, Vol.215, No.3, pp.403-410

Altschul, S.F.; Madden, T.L.; Schäffer, A.A.; Zhang, J.; Zhang, Z.; Miller, W. and Lipman, D.J. (1997). Gapped BLAST and PSI-BLAST: a new generation of protein database search programs. Nucleic Acids Research, Vol.25, No.17, pp.3389-402

Barral, P.; Batanero, E.; Palomares, O.; Quiralte, J.; Villalba, M. and Rodríguez, R. (2004). A major allergen from pollen defines a novel family of plant proteins and shows intra- and interspecies cross-reactivity. Journal of Immunology, Vol.172, pp.3644-3651

Bartolini, G.; Prevost, G. and Messeri, C. (1994). Olive tree germplasm: descriptor lists of cultivated varieties in the world. Acta Horticulturae, Vol.365, pp.116-118

Batanero, E.; Villalba, M. and Rodríguez, R. (1994). Glycosylation site of the major allergen from olive tree. Allergenic implications of the carbohydrate moiety. Molecular Immunology, Vol.31, pp.31-37 
Castro, A.J.; Bednarczyk, A.; Schaeffer-Reiss, C.; Rodríguez-García, M.I.; Van Dorsselaer, A.; Alché, J.D. (2010). Screening of Ole e 1 polymorphism among olive cultivars by peptide mapping and N-glycopeptide analysis. Proteomics, Vol. 10, No 5, pp.953-962

Chapman, M.D.; Pomés, A.; Breiteneder, H. and Ferreira, F. (2007). Nomenclature and structural biology of allergens. Journal of Allergy and Clinical Immunology, Vol.119, No.2, pp.414-420

Chapman, M.D.; Smith, A.M.; Vailes, L.D.; Arruda, K.; Dhanaraj, V. and Pomes, A. (2000). Recombinant allergens for diagnosis and therapy of allergic diseases. The Journal of Allergy and Clinical Immunology, Vol.106, pp.409-418

Chevenet, F.; Brun, C.; Banuls, A.L.; Jacq, B. and Christen, R. (2006). TreeDyn: towards dynamic graphics and annotations for analyses of trees. BMC Bioinformatics, Vol.7, pp.439

D’Amato, G.; Spieksma, F.T.; Liccardi, G.; Jager, S.; Russo, M.; Kontou-Fili, K.; Nikkels, H.; Wuthrich, B. and Bonini, S. (1998). Pollen-related allergy in Europe. Allergy, Vol.53, pp.67-78

de Castro, E.; Sigrist, C.J.A.; Gattiker, A.; Bulliard, V.; Langendijk-Genevaux, P.S.; Gasteiger, E.; Bairoch, A. and Hulo, H. (2006) ScanProsite: detection of PROSITE signature matches and ProRule-associated functional and structural residues in proteins. Nucleic Acids Research, Vol.34, pp.362-365

Ferreira, F.; Wallner, M. and Thalhamer, J. (2004). Customized antigens for desensitizing allergic patients. Advances in Immunology, Vol.84, pp.79-129

Finn, R.D.; Mistry, J.; Tate, J.; Coggill, P.; Heger, A.; Pollington, J.E.; Gavin, O.L. Gunesekaran, P.; Ceric, G. Forslund, K.; Holm, L.; Sonnhammer, E.L.; Eddy, S.R. and Bateman, A. (2010). The Pfam protein families database. Nucleic Acids Research, Database Issue 38, pp.D211-222

Gasteiger, E.; Gattiker, A.; Hoogland, C.; Ivanyi, I.; Appel R.D. and Bairoch A. (2003) ExPASy: the proteomics server for in-depth protein knowledge and analysis. Nucleic Acids Research, Vol.31, pp.3784-3788

Goodman, R.E. and Tetteh, A.O. (2011). Suggested Improvements for the Allergenicity Assessment of Genetically Modified Plants Used in Foods. Current Allergy and Asthma Reports, doi: 10.1007/s11882-011-0195-6

Guex, N. and Peitsch, M.C. (1997). SWISS-MODEL and the Swiss-PdbViewer: an environment for comparative protein modeling. Electrophoresis, Vol.18, No.15, pp.2714-2723

Hall, T.A. (1999). BioEdit: a user-friendly biological sequence alignment editor and analysis program for Windows 95/98/NT. Nucleic Acids Symposium Series, Vol.41, pp.95-98

Hamman-Khalifa, A.M.; Castro A.J.; Jimenez-Lopez, J.C.; Rodríguez-García, M.I. and Alché, J.D. (2008). Olive cultivar origin is a major cause of polymorphism for Ole e 1 pollen allergen. BMC Plant Biology, Vol.8, 10

Hanson, D.D.; Hamilton, D.S.; Travis, J.L.; Bashe, D.M. and Mascarenhas, J.P. (1998). Characterization of a pollen-specific cDNA clone from Zea mays and its expression. Plant Cell, Vol.1, pp.173-179

Hauser, M.; Roulias, A.; Ferreira, F. \& Egger, M. (2010). Panallergens and their impact on the allergic patient. Allergy, Asthma \& Clinical Immunology, Vol.6, pp.1- 
Jutel, M.; Jaeger, L.; Suck, R.; Meyer, H.; Fiebig, H. and Cromwell, O. (2005). Allergenspecific immunotherapy with recombinant grass pollen allergens. The Journal of Allergy and Clinical Immunology, Vol.116, pp.608-613

Laskowski, R.A.; MacArthur, M.W.; Moss, D.S. and Thornton, J.M. (1993). PROCHECK: A program to check the stereo-chemical quality of protein structures. Journal of Applied Crystallography, Vol.26, pp.283-291

Lauzurica, P.; Gurbindo, C.; Maruri, N.; Galocha, B.; Diaz, R.; Gonzalez, J.; García, R. and Lahoz, C. (1988). Olive (Olea europea) pollen allergens-I. Immunochemical characterization by immunoblotting, CRIE and immunodetection by a monoclonal antibody. Molecular Immunology, Vol.25, pp.329-335

King, T.P.; Hoffman, D.; Lowenstein, H.; Marsh, D.G.; Platts-Mills, T.A. and Thomas, W. (1994). Allergen nomenclature. WHO/IUIS Allergen Nomenclature Subcommittee. International Archives of Allergy and Immunology, Vol. 105, pp. 224-233

Kotchoni, S.O.; Jimenez-Lopez, J.C.; Gachomo, W.E. and Seufferheld, M.J. (2010). A new and unified nomenclature for male fertility restorer (RF) proteins in higher plants. PLoS ONE, Vol.5, No.12, pp.e15906

Melo, F. and Feytmans, E. (1997). Novel knowledge-based mean force potential at atomic level. Journal of Molecular Biology, Vol.267, No.1, pp.207-222

Melo, F. and Feytmans, E. (1998). Assessing protein structures with a non-local atomic interaction energy. Journal of Molecular Biology, Vol.277, No.5, pp.1141-1152

Mothes, N.; Horak, F. \& Valenta, R. (2004). Transition from a botanical to a molecular classification in tree pollen allergy: implications for diagnosis andtherapy. International Archives of Allergy and Immunology, Vol.135, pp.357-373

Orruño, E. and Morgan, M.R.A. (2011). Resistance of purified seed storage proteins from sesame (Sesamum indicum L.) to proteolytic digestive enzymes. Food Chemistry, in press

Piboonpocanun S, Malinual N, Jirapongsananuruk J, Vichyanond P, Thomas WR. (2006). Genetic polymorphisms of major house dust mite allergens. Clinical \& Experimental Allergy, Vol.36, pp.510-516

Radauer, C.; Bublin, M.; Wagner, S.; Mari, A. and Breiteneder, H. (2008). Allergens are distributed into few protein families and possess a restricted number of biochemical functions. Journal of Allergy and Clinical Immunology, Vol.121, pp.847852

Rodriguez, R.;Villalba, M.; Batanero, E.; González, E.M.; Monsalve, R.I.; Huecas, S.; Tejera, M.L. and Ledesma, A. (2002). Allergenic diversity of the olive pollen. Allergy, Vol.57, pp.6-16

Rodríguez, R.; Villalba, M.; Monsalve, R.I.; Batanero, E.; González, E.M.; Monsalve, R.I.; Huecas, S.; Tejera, M.L. and Ledesma, A. (2002). Allergenic diversity of the olive pollen. Allergy, Vol.57, pp.6-15

Salamanca, G.; Rodriguez, R. Quiralte, J.; Moreno, C.; Pascual, C.Y.; Barber, D. and Villalba, M. (2010). Pectin methylesterases of pollen tissue, a major allergen in olive tree. FEBS Journal, Vol.277, No.13, pp.2729-2739

Sastre, J. (2010). Molecular diagnosis in allergy. Clinical \& Experimental Allergy, Vol.40, No.10, pp.1442-1460

Scheiner, O.; Aberer, W.; Ebner, C.; Ferreira, F.; Hoffmann-Sommergruber, K.; Hsieh, L.S.; Kraft, D.; Sowka, S.; Vanek-Krebitz, M. and Breiteneder, H. (1997). Cross-racting 
allergens in tree pollen and pollen-related food allergy: implications for diagnosis of specific IgE. International Archives of Allergy and Immunology, Vol.113, pp.105-108

Shultz, J.L.; Kurunam, D.; Shopinski, K.; Iqbal, M.J.; Kazi, S.; Zobrist, K.; Bashir, R.; Yaegashi, S.; Lavu, N.; Afzal, A.J.; Yesudas, C.R.; Kassem, M.A.; Wu, C.; Zhang, H.B.; Town, C.D.; Meksem, K. and Lightfoot, D.A. (2006). The Soybean Genome Database (SoyGD): a browser for display of duplicated, polyploid, regions and sequence tagged sites on the integrated physical and genetic maps of Glycine max. Nucleic Acids Research, Vol.34(suppl 1), pp.D758-D765

Sigrist, C.J.A.; Cerutti, L.; de Castro, E.; Langendijk-Genevaux, P.S.; Bulliard, V.; Bairoch, A. and Hulo, N. (2010). PROSITE, a protein domain database for functional characterization and annotation. Nucleic Acids Research, Vol.38 (Database issue), pp.161-166

Smith, A.S.; Benjamin, D.C.; Hozic, N.; Derewenda, U.; Smith, W.A.; Thomas, W.R.; Gafvelin, G.; van Hage-Hamsten, M. and Chapman, M.D. (2001). The molecular basis of antigenic cross-reactivity between the group 2 mite allergens. The Journal of Allergy and Clinical Immunology, Vol.107, pp.977-984

Smith, W.A.; Hales, B.J.; Jarnicki, A.G. and Thomas W.R. (2001). Allergens of wild house dust mites: environmental Der p 1 and Der p 2 sequence polymorphisms. The Journal of Allergy and Clinical Immunology, Vol.107, pp.985-992

Stratford, S.; Barne, W.; Hohorst, D.L.; Sagert, J.G.; Cotter, R.; Golubiewski, A.; Showalter, A.M.; McCormick, S. and Bedinger, P. (2001). A leucine-rich repeat region is conserved in pollen extensin-like (Pex) proteins in monocots and dicots. Plant Molecular Biology, Vol.46, pp.43-56

Tang, B.; Banerjee, B.; Greenberger, P.A.; Fink, J.N.; Kelly, K.J. and Kurup, V.P. (2000). Antibody binding of deletion mutants of Asp f 2, the major Aspergillus fumigatus allergen. Biochemical and Biophysical Research Communications, Vol.270, pp.1128-1135

Thompson, J.D.; Higgins, D.G. and Gibson, T.J. (1994). CLUSTAL W: improving the sensitivity of progressive multiple sequence alignment through sequence weighting, position-specific gap penalties and weight matrix choice. Nucleic Acids Research, Vol.22, pp.4673-4680

Twell, D.; Wing, R.; Yamaguchi, J. and McCormick, S. (1989). Isolation and expression of an anther-specific gene from tomato. Molecular and General Genetics, Vol.217, pp.240-245

van Gunsteren, W.F.; Billeter, S.R.; Eising, A.A.; Hünenberger, P.H.; Krüger, P.; Mark, A.E.; Scott, W.R.P. and Tironi, I.G. (1996). Biomolecular Simulations: The GROMOS96 Manual and User Guide. Zürich, VdF Hochschulverlag ETHZ

van Ree R. (2004). Clinical importance of cross-reactivity in food allergy. Current Opinion in Allergy \& Clinical Immunology. Vol.4, pp.235-240

Villalba, M.; Batanero, E.; Lopez-Otin, C.; Sanchez, L.M.; Monsalve, R.I.; Gonzalez de la Pena, M.A.; Lahoz, C. and Rodriguez, R. (1993). The amino acid sequence of Ole e I, the major allergen from olive tree (Olea europaea) pollen. European Journal of Biochemistry, Vol.216, pp.863-869

Villalba, M.; López-Otín, C.; Martín-Orozco, E.; Monsalve, R.I.; Palomino, P.; Lahoz, C. and Rodríguez, R. (1990). Isolation of three allergenic fractions of the major allergen from Olea europaea pollen and N-terminal amino acid sequence. Biochemical and Biophysical Research Communications, Vol.172, pp.523-528

Wagner, S. and Breiteneder, H. (2002). The latex-fruit syndrome. Biochemical Society Transactions, Vol.6, pp.935-940 


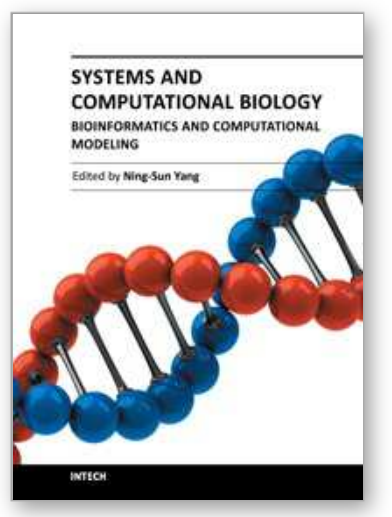

\section{Systems and Computational Biology - Bioinformatics and Computational Modeling}

Edited by Prof. Ning-Sun Yang

ISBN 978-953-307-875-5

Hard cover, 334 pages

Publisher InTech

Published online 12, September, 2011

Published in print edition September, 2011

Whereas some â€œmicroarrayâ€ or â€œbioinformaticsâ€ scientists among us may have been criticized as doing â€œcataloging researchâ€, the majority of us believe that we are sincerely exploring new scientific and technological systems to benefit human health, human food and animal feed production, and environmental protections. Indeed, we are humbled by the complexity, extent and beauty of cross-talks in various biological systems; on the other hand, we are becoming more educated and are able to start addressing honestly and skillfully the various important issues concerning translational medicine, global agriculture, and the environment. The two volumes of this book present a series of high-quality research or review articles in a timely fashion to this emerging research field of our scientific community.

\section{How to reference}

In order to correctly reference this scholarly work, feel free to copy and paste the following:

José Carlos Jiménez-López, Maria Isabel Rodríguez-García and Juan de Dios Alche (2011). Systematic and Phylogenetic Analysis of the Ole e 1 Pollen Protein Family Members in Plants, Systems and Computational Biology - Bioinformatics and Computational Modeling, Prof. Ning-Sun Yang (Ed.), ISBN: 978-953-307-875-5, InTech, Available from: http://www.intechopen.com/books/systems-and-computational-biology-bioinformaticsand-computational-modeling/systematic-and-phylogenetic-analysis-of-the-ole-e-1-pollen-protein-familymembers-in-plants

\section{INTECH}

open science | open minds

\author{
InTech Europe \\ University Campus STeP Ri \\ Slavka Krautzeka 83/A \\ 51000 Rijeka, Croatia \\ Phone: +385 (51) 770447 \\ Fax: +385 (51) 686166 \\ www.intechopen.com
}

\author{
InTech China \\ Unit 405, Office Block, Hotel Equatorial Shanghai \\ No.65, Yan An Road (West), Shanghai, 200040, China \\ 中国上海市延安西路65号上海国际贵都大饭店办公楼 405 单元 \\ Phone: +86-21-62489820 \\ Fax: $+86-21-62489821$
}


(C) 2011 The Author(s). Licensee IntechOpen. This chapter is distributed under the terms of the Creative Commons Attribution-NonCommercialShareAlike-3.0 License, which permits use, distribution and reproduction for non-commercial purposes, provided the original is properly cited and derivative works building on this content are distributed under the same license. 